\title{
COMPORTAMENTO DE NOVAS CULTIVARES DE CEBOLA (Allium copa L.) NO SISTEMA DE CULTIVO DE BULBINHO DE INVERNO EM RELAÇÃO AOS CULTIVOS CONVENCIONAIS
}

\section{WALDELICE OLIVEIRA DE PAIVA}

Engenheira Agrônoma

INPA

Orientador: PROF. DR. CYRO PAULINO DA COSTA

Dissertação apresentada à Escola Superior de Agricultura "Luiz de Queiroz", da Universidade de São Paulo, para obtenção do título de Mestre em Genética e Melhoramento de Plantas.

PIRACICABA

ESTADO DE SÃO PAULO - BRASIL

Março - 1980 
ii.

Aos meus pais, irmaos e ao meu marido,

$$
\text { ofereso }
$$


. iii.

\section{BIOGRAFIA DO AUTOR}

WALDELICE OLIVEIRA DE PAIVA, filha de waldemar Acioli de oliveira e Alice Soares de oliveira, nasceu em 13 de abril de 1951, em Santarém, PA. Em 1972, ingressou na Faculdade de Ciências Agrärias do Parâ, PA, obtendo o diploma de Engenheira Agrônoma em dezembro de 1975. Em 1976, foi con tratada pelo Instituto Nacional de Pesquisas da Amazônia

- INPA, para desenvolver trabalhos de pesquisa no setor de me Lhoramento de hortaliças, no Estado do Amazonas. 
- Ao Prof. Dr. Cyro Paulino da Costa, pela cessão dos dados com que foi executado o presente trabalho e pela dedicada orientação e incentivo;

- Ao Prof. Dr. Warwick Estevan Kerr pela oportunidade concedi da para realização do curso de Mestrado, quando diretor do Instituto Nacional de Pesquisas da Amazônia - INPA, e também pelo apoio e amizade;

- Aos Docentes do Departamento e Instituto de Genética da Escola Superior de Agricultura "Luiz de Queiroz", pelos ensinamentos ministrados;

- Aos colegas Hiroshi (Sandra) Noda pelas correções do manuscrito.

- Aos funcionários do Departamento e Instituto de Genética da Escola Superior de Agricultura "Luiz de Queiroz" pela manei ra atenciosa que sempre nos atendeu;

- Aos funcionários de campo do Departamento e Instituto de Ge nética, que com suas parcelas de trabalho contribuiram para a realização deste trabalho;

- Ao colega Dimas Menezes pelas sugestões; 
$\cdot v$.

- Ao esposo e amigo Engo Agro João Rodrigues de Paiva, por seu incentivo e apoio constante, e tambêm pela parcela de sugestões na confecção deste trabalho;

- Ao Instituto Nacional de Pesquisas da Amazônia - INPA, pela oportunidade de aperfeiçoamento. 
. vi.

INDICE

pagina

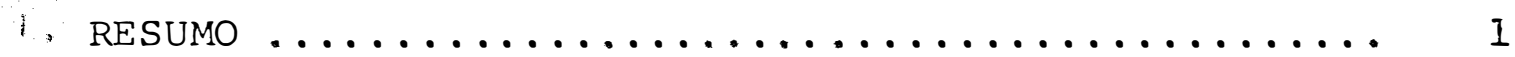

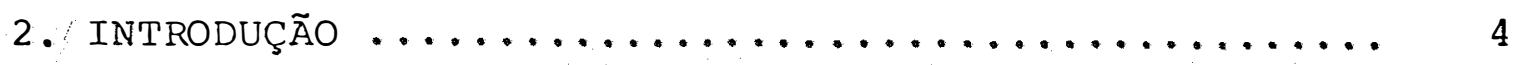

3. REVISÃo de LITERATURA ...................... 7

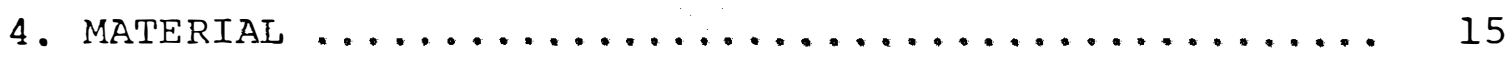

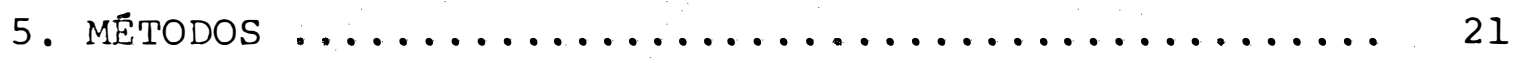

5.1. Condução dos Experimentos .............. 21

5.2. Delineamento Experimental .............. 24

5.3. Obtenção dos Dados Experimentais .......... 25

5.4. Análise Estatística ................. 26

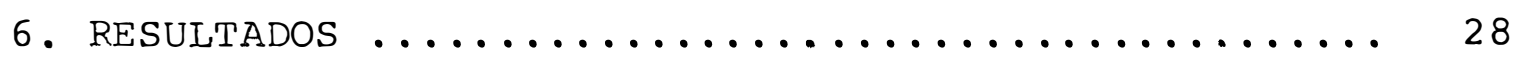

6.1. Cultura de Cebola de Inverno (S.C.I) ........ 28

6.2. Sistema de Cultivo de Bulbinho de verão (S.C.

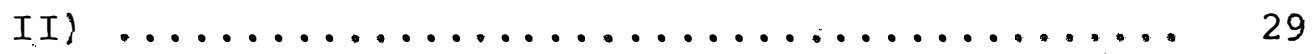

6.3. Sistema de Cultivo de Bulbinho de Inverno (S.

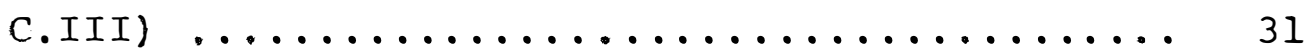

6.4. Análise Conjunta dos Sistemas de Cultivo .... 32

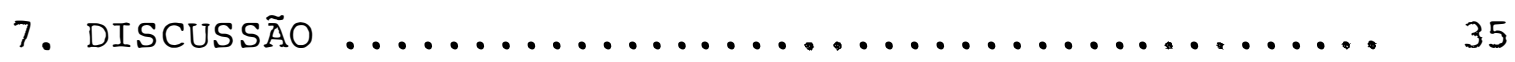

8. CONCLUSÕES .......................... 48

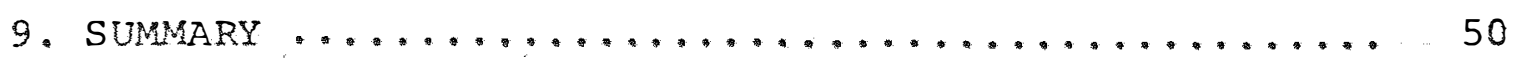


- vii.

pägina

10. LITERATURA CITADA ........................ 52

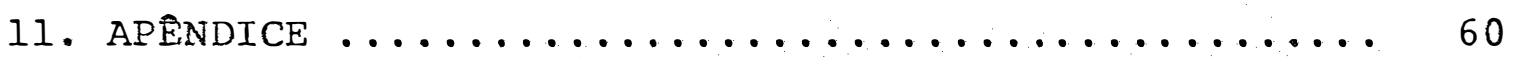

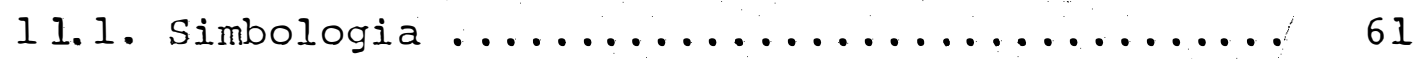

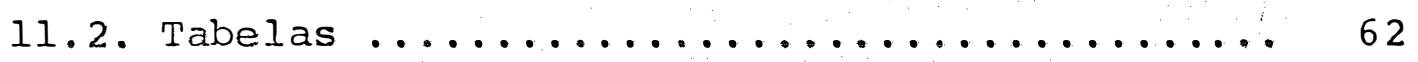

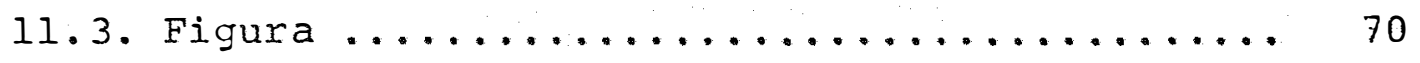




\section{LISTA DE TABELAS}

$\underline{\text { Tabela }}$

pāgina

01 - Valores e significâncias dos quadrados médios das análises de variância dos caracteres estu dados no delineamento de blocos ao acaso. Sis tema de cultivo de inverno. Piracicaba, SP, 1975

02 - Médias dos caracteres estudados para as culti vares de cebola. Sistema de cultivo de inver

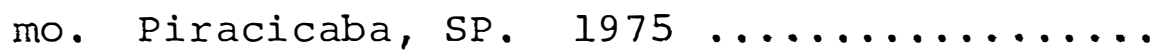

03 - Valores e significâncias dos quadrados médios das análises de variância dos caracteres estụ dados, no delineamento de blocos ao acaso.sis tema de Cultivo de Bulbinho de Verão. Pirací caba, SP. $1975 \ldots \ldots \ldots \ldots \ldots \ldots \ldots \ldots \ldots \ldots \ldots$

04 - Médias dos caracteres estudados para as culti vares de cebola. Sistema de Cultivo de Bulbi nho de Verão. Piracicaba, SP. 1975 .......

05 - Valores e significâncias dos quadrados médios das anālises de variância dos caracteres estú dados, no delineamento de blocos ao acaso.sis tema de Cultivo de Bulbinho de Inverno. Pira cicaba, SP. $1979 \ldots \ldots \ldots \ldots \ldots \ldots \ldots \ldots$ 
.$i x$.

06 - Médias dos caracteres estudados para as culti vares de cebola. Sistema de Cultivo de Bulbi nho de Inverno. Piracicaba, SP. $1979 \ldots \ldots$

07 - Valores e significâncias dos quadrados médios da análise de variância conjunta relativas aos caracteres estudados, no delineamento de blocos ao acaso com tratamentos comuns e três sistemas de cultivo. Piracicaba, SP. $1974 /$

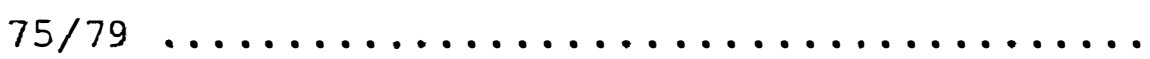

08 - Médias dos caracteres estudados para as cultí vares de cebola nos três sistemas de cultivo.

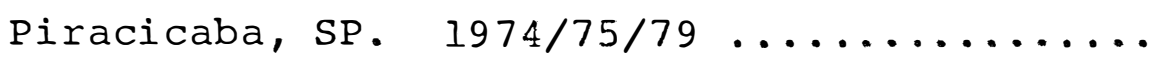


Figura

pägina

01 - Diagrama esquemático do sistema de cultivo de bulbinho de inverno em contraste com os siste mas convencionais $\ldots \ldots \ldots \ldots \ldots \ldots \ldots$ 
1. RESUMO

o presente trabalho teve por objetivo caracterizar o comportamento de novas cultivares de cebola, submetidas aos sistemas de cultivos denominados: cultivo de inverno (S.C.I), sistema de cultivo de bulbinho de verão (S.C.II) e sistema dé cultivo de bulbinho de inverno (S.C.III), visando tambēm, comparar o último em relação aos cultivos convencionais.

O material utilizado compreendeu dez cultivares de cebola e um híbrido inter'varietal. Os ensaios foram no delineamento de blocos ao acaso, relizados em Piracicaba e avaliou-se os caracteres de florescimento prematuro, plantas improdutivas, número de bulbos comerciais e produção.

Nos sistemas convencionais de cultivo de inver no e de bulbinho de verão, a cultivar Roxa Chata apresentou o maior valor de plantas com florescimento prematuro. No siste- 
ma de cultivo de bulbinho de inverno as cultivares Pira Tropi cal seleções $A / R$ e $A / C$ foram superiores as demais e também ao controle; Pira Dura foi a cultivar com menor tendência ao flo rescimento prematuro. Quanto a ocorrência de plantas improdu tivas, no sistema de cultivo de bulbinho de verão, a cultivar Barreiro SMP-III destacou-se pelo elevado número de plantas improdutivas em contraste com os menores valores da Roxa Chata; as cultivares Baia do Cedo SMP-IV e Pira Ouro apresentaram o maior e o menor valor, respectivamente, no sistema de cultivo de bulbinho de inverno. Na avaliação do número de bul bos comerciais no sistema de cultivo de inverno, não foram de tectadas diferenças significativas entre as cultivares e o controle, entretanto, no sistema de cultivo de bulbinho de ve rão a cultivar Barreiro SMP-III apresentou comportamento infe rior. No sistema de cultivo de bulbinho de inverno, as culti vares Pira Lopes, Pira Ouro e Pira Dura destacaram-se como as melhores em relação ao nümero de bulbos comerciais.

Quanto ao carāter produção de bulbos, destacaram-se como as mais produtivas as cultivares Barreiro SMP-III, Roxa Chata e Baia do Cedo SMP-IV, nos sistemas de cultivo de inverno, cultivo de bulbinho de verão e cultivo de bulbinho de inverno, respectivamente.

O sistema de cultivo de bulbinho de inverno,pe Ios resultados encontrados evidenciou a possibilidade de sua aplicação na produção de semente pelo esquema anual ao invés 
.3 .

do bianual. Outra vantagem é quanto a sua integralização ao sistema de cultivo de verão, surgindo a possibilidade de colheita de duas safras ao ano pelo cebolicultor.

o florescimento prematuro foi o caráter que maior influência exerceu no comportamento das cultivares quan do submetidas aos sistemas de cultivos. Sugere-se alterações no plantio dos bulbinhos de cultivares mais sensíveis ao florescimento prematuro, no sistema de cultivo de bulbinho de in verno, para o mês de agosto a fim de evitar o aparecimento des te fenômeno. 
O cultivo de cebola no Estado de são Paulo, ca racteriza-se por apresentar três sistemas distintos de cultivo em três períodos diferentes de plantio, que são: cultura de verão, cultura pela técnica de bulbinho de verão e cultura de inverno.

A cultura de verão inicia com plantios de dezembro a janeiro, utilizando como alternativas a semeadura dí reta ou transplante, possibilitando a colheita da safra até junho (COSTA, 1978).

A cultura pela técnica de bulbinho de verão, realizada principalmente na região de Piedade, possibilita co lheitas nas entressafras, isto é, de maio a junho. Trata-se de uma técnica de maior custo operacional porque envolve o culti vo da cebola em duas etapas. A primeira etapa, efetuada no final do segundo semestre, caracteriza-se pela obtenção dos 
bulbinhos através de semeaduras densas e diretas. Após a colheita os bulbinhos são armazenados e depois classificados pa ra o plantio. A segunda etapa consiste no plantio de bulbinhos nos meses de fevereiro a março, e a colheita dos bulbos prolongando-se até junho.

A cultura de cebola pelo sistema de cultivo de inverno, normalmente é feita procedendo-se a semeadura direta ou transplante. A semeadura é feita nos meses de abril-junho e a colheita a partir de setembro, prolongando-se até novembro.

Em todas as técnicas de cultivo de cebola as cultivares mostram comportamentos diferenciais, uma vez que, diferentes combinações de fatores ambientais estão presentes em cada época de plantio. Fatores como fotoperiodismo, tempe raturas, conservação, dormência e maturação limitariam o uso de uma única cultivar em todos os sistemas de cultivo.

A identificação de fatores favoráveis e limitantes às cultivares, permitiriam a obtenção de informações pa ra direcionar programas de melhoramento ou ajuste de manejo ambiental, tornando mais eficiente a utilização dos sistemas de cultivo de cebola no Estado de são Paulo.

Outra opção para o cultivo de cebola, seria através do sistema de cultivo de bulbinho de inverno. A obtenção dos bulbinhos iniciaria com a semeadura no período de 
novembro-dezembro, aplicando-se a mesma técnica de obtenção dos bulbinhos do sistema de cultivo de bulbinho de verão. Alternativamente, os bulbos com peso inferior a 50 gramas, produzidos na cultura de verão, poderiam ser aproveitados, efetuando-se o seu armazenamento durante o inverno e o plantio a. partir do mês de julho extendendo-se até agosto, culminando com a colheita dos bulbos comerciais nos meses de outubro e. novembro.

o presente trabalho visa caracterizar um novo sistema de cultivo de cebola, o ciltivo de bulbinno de inverno, em relação aos sistemas de cultivos convencionais. Propõe-se, também, analisar o comportamento de novaś cultivares de cebola, quando submetidas aos sistemas de cultivos mencio nados, estabelecendo suas limitaçōes e potencialidades. 


\section{REVISATO DE LITERATURA}

No Estado de São Paulo, a cultura de cebola ca racteriza-se por três períodos de cultivo, os quais, de acordo com DIAS e COSTA (1968) receberam a denominação de Cultura do Cedo por mudas, Cultura de bulbinhos e Cultura de inverno. Recentemente, o termo cultura do cedo foi substituído por cul tivo de verão. Os mesmos autores relatam que na região de São José do Rio Pardo, SP, os cebolicultores utilizam desde 1962 a cultivar Texas Grano que destaca-se como a mais promis sora no cultivo de verão. O plantio inicia com semeaduras em janeiro, transplante de mudas 40 dias após a semeadura e colheita dos bulbos em junho.

Os fatores ambientais mais criticos para o sis tema de cultivo de verão, utilizando-se cultivares de dias curtos, segundo ABDALA (1963) e MELO (1978) referem-se às con dições de fotoperiodismo exageradas e temperaturas elevadas. 
A influência negativa destes fatores resultam em plantas improdutivas que permanecem vegetando por todo o ciclo, ou causam a bulbificação precoce das mudas no período de pré e póstransplante. Segundo CosTA (1978), quando a cultivar Excel é utilizada no plantio com semeadura direta, bulbifica precocemente, resultando em bulbos com pesos inferiores a 10 gramas. Entretanto, algumas cultivares parecem ser insensiveis ao fotoperiodismo e temperaturas elevadas, apresentando mudas com continuidade vegetativa e alta sobrevivência pós-transplante, como é o caso de Conjumatlan. Conforme MELO (1978), a seleÇão efetuada nas cultivares Baia do Cedo e Composto Baia para incrementar a sobrevivência das mudas no período pós-transplante, aumentou consideravelmente o indice de bulbos menores que $50 \mathrm{~g}$.

FRAPPEL (1973) e WANDERLEY et atii (1971) obser varam que em altas densidades de plantio os bulbos ficam inaceitavelmente pequenos pela competição entre plantas; que o tamanho influencia diretamente o peso dos bulbos, e este "è bastante influenciado pelo ambiente.

A cultura da cebola pela técnica de bulbinho de verão, no Brasil, envolve duas etapas distintas. A primei ra etapa consiste na semeadura densa e direta na segunda quin zena de julho, prolongando-se até a primeira quinzena do mês seguinte, sendo os bulbinhos colhidos em novembro, quando então, são selecionados pelo tamanho e armazenados em galpões 
ventilados até fevereiro, em seguida são classificados pelo diâmetro. A segunda etapa, refere-se ao plantio dos bulbinhos na segunda quinzena de fevereiro até a primeira quinzena de março, e colheita dos bulbos comerciais em maio

(DIAS, 1963 e 1966).

WALKER et alii (1944) indicam como vantajosa a cultura de cebola pelo processo de bulbinho, por permitir colheita mais precoce que o processo normal, possibilitando tam bém, o desenvolvimento mais vigoroso da planta, que de certa forma contribui para a menor incidência de doenças e pragas. Informações detalhadas sobre esta tēcnica, referentes à prodụ ção de bulbinhos e épocas de plantio, são dadas por DIAS (1962, 1963 e 1966).

Estudos sobre o caráter tamanho de bulbinho re lacionado a aiferentes épocas de plantio, foram feitos por DIAS et alii (1961), CAMARGO e VIANA (1964) e VALE (1972) que encontraram alta correlação positiva entre tamanho de bulbi nho e produção. A melhor eficiência dos bulbinhos maiores, deve-se ao fato de que os mesmos apresentam maiores reservas nutritivas, proporcionando melhor conservação e mais fácil ma nejo. Por outro lado, TROMICKOVA (1977) constatou que o tama nho do bulbo na colheita foi muito mais afetado pelo tamanho do bulbinho e época de plantio do que pelo uso de diferentes cultivares. 
O caráter conservação dos bulbinhos é de vital importância para as cultivares de cebola, pois o período de armazenagem coincidindo com os meses de alta umidade e temperaturas elevadas, favorecem a brotação e o apodrecimento dos bulbinhos, embora a eficiência do armazenamento seja também, diretamente relacionada com a dormência. AUNG e PETERSON (1974) verificaram em linhagens de cebolas, obtidas do progra ma de melhoramento da Universidade de Michigan, nos Estados Unidos, que o caráter dormência de bulbinhos é correlacionado com o conteúdo de ácido giberélico, havendo tendência dos bu binhos que apresentam dormência mais prolongada possuírem mai ores teores. Observaram também, que não existem diferenças no período de dormência entre as linhagens. Uma técnica suge rida por HOPEN et alii (1971) e KARMARKAR e JOSHI (1941), através do uso de temperaturas de 5 a $25^{\circ} \mathrm{C}$ em intervalos de um a dez dias apôs a colheita, obtem-se substancial redução no período de dormência. A população Baía Periforme específica para o cultivo por bulbinho apresenta dormência, desse modo, evitando a brotação dos bulbinhos nas condições de umidade e temperaturas elevadas que ocorrem durante o período de armaze nagem. Este período de dormência tem a duração de dois meses, segundo VALE (1972). Portanto, a produção dos bulbinhos não deve ser muito tardia e fim de possibilitar o plantio no início de fevereiro.

Na cultura de cebola de inverno nas condições climáticas do Estado de São Paulo, o transplante das mudas é 
feito entre os meses de junho e julho, ocorrendo a colheita no mès de novembro. A formação dos bulbos ocorre na fase de temperatura e fotoperíodo crescente, que são fatores adequados ao seu desenvolvimento, desta forma, contribuindo sensivelmente para a redução da ocorrência de plantas improdutivas. Entretanto, de acordo com CAMPOS (1966), quando a cultivar Ba ia Periforme é cultivada nestas condições ocorre grande incidência de florescimento prematuro, limitando o seu cultivo, pois este caráter é indesejāvel na produção de bulbos comerciais.

THOMPSON e SMITH (1938) salientam que tanto os bulbos armazenados quanto as plantas no campo, sob condições de baixas temperaturas, podem ser induzidas à florescerem pre cocemente. As temperaturas situadas entre $9^{\circ}$ e $13^{\circ} \mathrm{C}$, observa das por HOLDSWORTH e HEATH (1950), parecem ser criticas para induzir o florescimento prematuro. Recentemente, tem-se observado que a associação de tratos culturais com tratamentos químicos, proporcionam efeitos promissores no controle do florescimento prematuro; o uso de hidrazida maleica em baixas concentrações, anulam o aparecimento do fenōmeno (SINNADURAI et alii, 1971).

Efetuando seleção massal contra o florescimento prematuro, DIAS e COSTA (1967) discorreram sobre a eficiência obtida em um ciclo de seleção em uma população de cebola (Allium cepa L.), objetivando melhor adaptação desta po- 
pulação para as condições de são Paulo. DIAS et alii (1969) citam que das plantas originadas de bulbos que não' sofreram processo de indução ao florescimento por baixas temperaturas, florescem somente aquelas que possuam genótipos pouco exigente à temperaturas baixas, eliminando-se portanto, gradativamente, os genōtipos com maior exigência de baixas temperaturas para o florescimento.

A planta jovem de cebola só inicia o processo de bulbificação se as condições ambientais são favoráveis, nes te caso, os fatores mais importantes são o comprimento do dia e temperatura. - CosTA (1964) verificou que nas condições climáticas de São Paulo, as semeaduras feitas nomès de abril com material do grupo Baia Periforme, proporcionam melhores produçöes de bulbos de cebola. Semeaduras feitas antes deste período apresentam alta frequència de plantas improdutivas , principalmente em anos que ocorram baixas temperaturas.

o cultivo de cebola pelo sistema de bulbinho de inverno é uma técnica usada principalmente nos paísés situados em latitudes acima do paralelo $40^{\circ}$, onde o período de cultivo da cebola é curto. Descrições detalhadas sobre os mé todos utilizados para produção, colheita, armazenamento e classificação dos bulbinhos são dadas por WALKER (1944), JONES e MANN (1963). Normalmente, a maioria dos plantios usando os bulbinhos são feitos manualmente, isto porque, o uso de mäquinas mostrou-se inadequado por exigir bulbinhos de tama- 
nho uniforme e também, porque as máquinas não espaçavam os bülbinhos uniformemente nas linhas e nem os colocavam na posi ção correta (COLBY et alii, 1945).

O florescimento prematuro tem sido o maior pro blema para o cultivo de cebola pela técnica de bulbinho de in verno, porque diferentes fatores, tais como, temperatura de estocagem e tamanho dos bulbinhos, tipo de cultivar usado e condições de cultivo; influenciam a manifestação deste caráter. O armazenamento dos bulbinhos é feito no período de inverno; quando estes são rigorosos, podem provocar a vernaliza ção dos bulbinhos, induzindo o florescimento pós-plantio. Con forme WALKER (1944), ROBERTS e STRUCKMEYER (1951), é prática comum no hemisfério norte aquecer os bulbinhos para desvernaliza-los, pois os bulbinhos que iniciaram o desenvolvimentode escapos florais, induzidos por baixas temperaturas, revertem o processo quando colocados sob regime de temperaturas elevadas. HEATH (1943) verificou que bulbinhos de maiores diâme$\operatorname{tros}(15,8 \mathrm{~mm}-20,6 \mathrm{~mm}$ à $25,4 \mathrm{~mm})$ são mais suscetíveis ao. florescimento prematuro do que bulbinhos de menores diâmetros (12,5-15,8 mm à 14,2-19,0 mm). Ainda, segundo o autor, os bulbinhos maiores quando submetidos a baixas temperaturas de armazenagem são também, os mais propensos a florescerem preco cemente. As condições estacionais críticas para a indução de florescimento prematuro, são as mesmas que influenciam o aparecimento do caráter na cuitura de cebola de inverno. 
O processo de bulbinho foi introduzido no Brasil, mais específicamente no Estado de São Paulo, pelo Setor de Melhoramento de Hortaliças do Departamento de Genética da ESALQ/USP, Piracicaba. E, desde 1952, as pesquisas estiveram voltadas para o sistema de cultivo de bulbinho de verão, não sendo conhecidos, até o momento, trabalhos nacionais abordando o uso do sistema de cultivo de bulbinho de inverno. Explí ca-se a inexistência de trabalhos desta natureza pelo fato de que o cultivo utilizando a técnica de bulbinho ser onerosa. No Brasil, está técnica só é economicamente viāvel, porque a colheita dos bulbos nos plantios de verão coincide com o período de entressafras, atingindo preços compensadores.

Existe entretanto, a possibilidade do uso de bulbos com pesos inferiores a $50 \mathrm{~g}$, originados do cultivo de verão e, que não se desenvolveram devido uma extrema competição entre as plantas provocadas pela falta de precisão na semeadura direta. Assim, o cultivo de bulbinho de inverno terá condições de tornar, num futuro próximo, um método barato e eficiente de produção de cebola. 
4. MATERIAL

Para o desenvolvimento do presente trabalho, foram utilizados dez cultivares de cebola e um híbrido intervarietal, obtidos pelo Setor de Hortaliças do Instituto de Ge nética da Escola Superior de Agricultura "Luiz de Queiroz", da Universidade de são Paulo, Piracicaba, cuja origem e características são a seguir descritas:

- Baia do Cedo SMP - IV

E origināria da população Baia Perifórme Lacides que foi submetida a quatro ciclos de seleção massal, para adaptação às condiçōes de cultivo de verão e de transplante de mudas.

Segundo DIAS e COSTA (1968), a Baia do Cedo ca racteriza-se por não apresentar bulbificação precoce na fase juvenil, quando ocorre fotoperiodos acima de 12 horas, e pela 
capacidade em produzir bulbos comerciais em condições de temperatura e fotoperíodos decrescentes, atē junho, constituindo-se numa cultivar pertencente ao grupo de dias curtos. Apre senta bulbos de coloração amarelo-baia, formato bojudo, de conservação intermediāria, com teores de sōlidódos solūveis em torno de $7 \%$ de brix.

O código SMP-IV significa seleção massal em Pi racicaba, quarto ciclo.

- Barreiro SMP - III

A cultivar Barreiro é cultivada há várias déca das por cebolicultores do Estado de Minas Gerais, onde especu la-se que sua origem seja italiana. Pertence ao grupo de cebola de dias curtòs, porēm, com maturaçāo tardia. Apresenta bulbos de formato esférico ou globular, coloração roxa clara, com conservação inferior às Baias Periformes. Segundo SILVA (1976), apresenta resistência ao Mal de Sete Voltas, causado pelo fungo Colletotrichum gloeosporioide Penz. (Sensu ARX, 1957) e suscetíbilidade ao fungo causador da Raiz Rosada (Pyrenochaeta terrestris (Hans) Gorenz, J.C. Walker, Larson).

E uma cultivar caracterizada por florescer com exigência de temperaturas amenas, como as prevalecentes nas condições de inverno do Estado de são Paulo.

o código SMP-III, significa seleção massal em 
Piracicaba, terceiro ciclo.

\section{- Pira Tropical}

Foi obtida através de três ciclos de seleção massal, para a cultura de verão, a partir da população $F_{5}$ (Ba ia do Cedo x Conjumatlan). A geração $F_{1}$ originou-se de cruzamentos naturais, iniciando-se os ciclos de seleção massal no ano de 1972 .

Apresenta bulbos de coloração amarela com duas seleções distintas para formato, achatado e redondo; a conser vação dos bulbos é equivalente ào grupo Baia. E recomendada para plantios de verão, devido florescer prematuramente a tem peraturas baixas nas condições de inverno de são Paulo.

\section{- Pira Ouro}

Esse material resulta originalmente do cruzamento de plantas macho estéril de Baia Periforme com a cultivar Barreiro, encontrando-se atualmente na quinta geração, após a hibridação.

As populações segregantes foram selecionadas para bulbos de coloração amarelo, formato globular, e apresen ta conservação equivalente a Baia Periforme. Apresenta maturação intermediária entre Baia Periforme e Barreiro, sendo considerada resistente ao Mal de Sete Voltas. Sua exigência 
em temperatura para florescimento prematuro na fase vegetativa, é equivalente a Baia Periforme.

\section{- Composto Baia Bulbinho}

E uma cultivar resultante do intercruzamento, no esquema de "polycross", de dez melhores populações de Baia Periforme do Rio Grande do Sul. O material foi submetido à seleção para adaptação ao sistema de cultivo pelo método de bulbinho.

Apresenta características similares ao grupo Baia Periforme, destacando-se pela uniformidade de maturação dos bulbos e marcante dormência; fatores críticos para o sucesso da técnica de bulbinho.

- Baia Precoce de Piracicaba

População de cebola Baia, obtida através de se leção massal da Baia Lacides. Segundo CosTA (1967), é adaptạ da para o cultivo de bulbinho de verão.

Esta: cultivar distingue-se da Baia Lacides, por ser mais precoce, apresentar menor número de bulbos perfi Ihados, maior uniformidade e melhor adaptação no cultivo de cebola por bulbinho. 


\section{- Roxa Chata}

Constitui a população Conjumatlan Roxa SMP-III, com três ciclos de seleção massal para cultura de verão, originada do germoplasma Conjumatlan Roxa Morada. A variedade Conjumatlan, conforme COSTA (1978), é de procedência do México e floresce precocemente nas condições de São Paulo.

A seleção da cultivar Roxa Chata dirigiu-se principalmente contra o caráter plantas improdutivas. Apresenta bulbos de coloração roxa escura, com completa ausêncía de dormência e conservação, equivalente aos do híbrido de cebola Granex.

Entre as novas cultivares é a que floresce com maior facilidade; recomendada para a cultura de verão pois é incapaz de bulbificar na fase juvenil, mesmo em condições de temperaturas e fotoperiodòs críticos.

\section{- Pira Lopes}

Cultivar obtida originalmente pelo intercruzamento de plantas dos seguintes híbridos intervarietais: Baia Periforme Precoce de Piracicaba selecionada para bulbinho, co mo linha A e cruzada com Barreiro, com Texas Grano, com Eclip se e com Red Creole. Após o intercruzamento, constituiu - se numa única população, que foi selecionada durante quatro gera ções para bulbos de coloração amarelo, formato arrendondado . 
Apresenta conservação superior à cultivar Baia Periforme.

Sua maturidade é intermediāria entre as cultivares Baia e Barreiro, possuíndo marcante retenção de escamas.

\section{- Pira Dura}

Essa cultivar resulta originalmente do cruzamento de Baia Periforme Precoce de Piracicaba, linha A com Red Creole. As populações segregantes foram selecionadas mas salmente para búlbos de coloração amareło, formato arredondado ou achatado, sendo o último usado no presente trabalho. Sua principal característica é a extrema firmeza dos bulbos, alto teor de sólidos solúveis e retenção de escamas, tendo co mo padrão a cultivar Red Creole. Os bulbos desta cultivar con servam-se por um período de até 6 meses em condições normais de armazenamento. Possue exigências de temperaturas para flo rescer equivalentes a Baia Periforme.

- F (Baia x Barreiro)

Eum híbrido intervarietal em que se utilizou o macho estéril da cultivar Baia Periforme Precoce de Piracicaba, com a Barreiro como polinizadora. Apresenta bulbos de coloração rosada, formato arredondado e maturação intermediāria entre as cultivares paternais. E resistente ao Mal de Se te Voltas e manifesta acentuada heterose, conforme constatação de costa e DIAS (1967). 


\subsection{Condução dos Experimentos}

Os experimentos foram conduzidos no Campo Expe rimental do Instituto de Genética da ESALQ/USP, em Piracicaba, $\mathrm{SP}$, latitude de $22^{\circ} 42^{\prime} 30^{\prime \prime} \mathrm{S}$.

No primeiro experimento utilizou-se o sistema de Cultivo de Cebola de Inverno (S.C.I.), onde as mudas foram produzidas em canteiros, previamente adubados, utilizando-se 5 gramas de sementes por metro quadrado, iniciado em 09 de ju nho de 1975. O transplante das mudas para o campo foi feito aos 50 dias após a data da semeadura, no espaçamento de $10 \mathrm{x}$ $50 \mathrm{~cm}$.

A adubação química utilizada, constituiu-se de 50 gramas por metro de sulco da fórmula 8:16:8. Posteriormen te, foram feitas adubações nitrogenadas em cobertura, quando necessārias. A irrigação foi feita por infiltração numa fre- 
quência de uma ou duas aplicações semanais, a fim de manter a umidade ideal do solo e o bom desenvolvimento vegetativo das plantas de cebola. Foi feito, ainda, os seguintes tratos cul turais: capinas manuais, pulverizações semanais com fungicidas e inseticidas. A colheita dos bulbos foi realizada no pe ríodo de 5 a 17.11 .1975$.

o experimento utilizando o sistema de cultivo de bulbinho de verão (S.C.II.), iniciou-se com semeaduras em faixas de $15 \mathrm{~cm}$, empregando-se 1 grama de semente por metro de faixa, no período de 15 a 30.07.1974. Os bulbinhos foram obtidos em 1-15.11.1974 e armazenados até fevereiro de 1975, quando, então, foram limpos e classificados por tamanho de pe neiras, obedecendo a metodologia apresentada por DIAS (1966).

Antes do plantio, os bulbinhos foram tratados com fungicidas, para evitar o apodrecimento. No experimento utilizou-se apenas os bulbinhos classificados na peneira no 3, sendo plantados em 08.03.1975, no espaçamento convencional. A adubação química constou de 50 gramas por metro de sulco da förmula 4:30:20. Quando necessārio foram ministradas adubações nitrogenadas complementares.

As pulverizações com fungicidas e inseticidas foram semanais. As irrigações foram aplicadas com frequência de duas por semana, por aspersão, na obtenção de bulbinhos, e por sulco no plantio definitivo. Para o controle de ervas in vasoras utilizou-se herbicidas de pré e pós-emergência. A co 
lheita de bulbos comerciais foi iniciada em 26.05.1975, com as cultivares mais precoces, prolongando-se até 24.06.1975, quando o experimento foi encerrado.

O sistema de cultivo de bulbinho de inverno (S. C.III), constitui o terceiro experimento. Foi iniciado na: primeira quinzena de dezembro de 1978, efetuando-se semeadura em faixas com 0,5 gramas de sementes por metro de faixa, sendo as faixas previamente adubadas com esterco curtido.

No controle de ervas invasoras de folhas estreitas, utilizou-se de aplicações do herbicida em pré-emer gência. O experimento em questão, originalmente tinha a fina lidade de produzir cebola pela técnica alternativa de semeadu ra direta na cultura de verão. Todavia, nos locais onde houve adensamento de sementes, provocadas por falhas mecânicas, ocorreu competição entre as plantas, favorecendo a formação de bulbos pequenos e sem valor comercial. Os bulbos com peso inferior a 50 gramas, foram classificados segundo metodolo gia apresentada por DIAS (1966); os pertencentes à peneira no 3 armazenou-se em galpões, no início de março até a segunda quizena de junho de 1979.

O plantio dos respectivos bulbinhos foi efetua do em 17.06.1979; adotando-se a mesma metodologia utilizada na cultura de bulbinho de verão, inclusive quanto aos tratos culturais. A colheita dos bulbos de cebola efetuou-se em uma 
única vez, finalizando-se o experimento em 31.10.1979.

As cultivares e o híbrido intervarietal, utili zados em cada um dos três sistemas de cultivo, foram relacionados da seguinte maneira:

Cultivares

Baia do Cedo SMP-IV

Barreiro SMP-III

Pira Tropical $A / R$

Pira Tropical A/C

Pira Ouro

Composto Baia Bulbinho

Baia Precoce de Piracicaba

Roxa Chata

Pira Lopes

Pira Dura

$F_{1}$ (Baia x Barreiro)..
Sistema de Curtivo S.C.I; S.C.II; S.C.III S.C.I; S.C.II; S.C.III S.C.I; S.C.II; S.C.III S.C.III S.C.I; S.C.II; S.C.III S.C.I; S.C.II; S.C.I; S.C.II; S.C.I; S.C.II; S.C.I; S.C.III S.C.I; S.C.III S.C.I; S.C.II;

\subsection{Delineamento Experimental}

O delineamento experimental utilizado nos três sistemas de cultivo, foi o de blocos ao acaso. No experimento S.C.I foram avaliadas 9 cultivares e o híbrido intervarietal em 4 repetições, para O S.C.II avaliaram-se 7 cultivares e o híbrido intervarietal ' com 4 repetiçōes, enquanto que no experimento S.C.III foram avaliados 7 cultivares em 8 repetiçoes. 
As parcelas foram constituídas de $2,00 \mathrm{~m}^{2}$, com 40 plantas na área ütil.

5.3. Obtenção dos dados experimentais

De cada cultivar, nos três sistemas de culti vo, foram obtidos dados dos seguintes caracteres:

a. Florescimento prematuro: expresso pelo núme ro de plantas que emitiram haste floral durante o período de desenvolvimento vegetativo da cultura, em seguida esses dados foram transformados em porcentagem para uma população ídeal de 40 plantas por parcelas.

b. Plantas improdutivas: representado pelo nūmero de plantas que não formaram, bulbos até a colheita e que foram eliminadas. Este caráter foi expresso em porcentagem em relação ao total de 40 plantas da parcela.

c. Bulboss comerciais: expresso pelo nümero de plantas que resultaram em bulbos de qualidade comercial. A título de comparação das médias, os dados estão apresentàdos em porcentagem de bulbos comerciais para uma população ideal de 40 plantas por parcela.

d. Produção: corresponde ao peso total de bulbos comerciais por parcela de $2,00 \mathrm{~m}^{2}$ de ärea, após terem sido eliminadas as raízes e folhas. Expresso em quilogramas por parcela de $2,00 \mathrm{~m}^{2}$. 


\subsection{Anālise estatística}

As análises individuais de variância dos siste mas de cultivo e a análise conjunta, foram feitas segundo meto dologias apresentadas por STPEEL e TORRIE (1960) e PIMENTEL GO MES (1978).

No teste de comparação das médias das cultivares, nas análises individuais, utilizou-se o teste " $t$ " para comparações com a média da cultivar Baia do Cedo, que serviu como controle. No teste de comparação das médias na análise conjunta, utilizou-se o teste de Tukey, neste caso, as médias sofreram um ajuste especial conforme recomendação de PIMENTEL GOMES (1978).

Na apresentação das médias utilizou-se os valo res reais e biológicos. As diferenças estatísticas detectadas pelo teste " $t$ " e Tukey foram feitas com os dados transformados.

O caráter expresso em nümero foi analisado com os-dados experimentais transformados para $\sqrt{y}$, sendo y $\circ \mathrm{nu}-$ mero de bulbos comerciais, segundo recomendações de SNEDECOR (1946). Os dados expressos em porcentagem foram inicialmente codificados, multiplicando-os pelo valor 1000, em seguida transformados para $\log x$, onde $x$ corresponde aos caracteres porcentagem de plantas florescidas e porcentagem de plantas improdutivas (STELL e TORRIE, 1960). 
.27 .

No caso de porcentagem de $0 \%$, adotou-se o critério sugerido por BARTLETT (1947), ajustando para valores de $1 / 4(\mathrm{n})$, sendo $\mathrm{n}$ igual ao nümero total de plantas dentro da parcela; utilizou-se também, o mesmo sistema de codificação anterior, antes da transformação dos dados para log $\mathbf{x}$. 
6.1. Cultura de cebola de inverno (S.C.I)

A análise de variância pará os quatro caracteres no S.C.I encontram-se na Tabela 1. Verifica-se que houve diferenças significativas ao nível de 58 de probabilidade, de tectadas pelo teste $F$, para os caracteres florescimento prema turo e produção; não foram porém detectadas diferenças signi-ficativas para os demais caracteres.

Os coeficientes de variação das anālises individuais no S.C.I variaram de 3,31 a 32,778 , sendo que para 0 caräter plantas improdutivas, expresso em porcentagem, apresentou maior valor, enquanto para o número de bulbos comerciais apresentou menor valor.

A comparação entre as médias das cultivares e - controle (Baia do Cedo SMP-IV) através do teste "t", ao nível de $5 \%$ de probabilidade, encontram-se na Tabela 2. Para o 
carāter florescimento prematuro; observa-se que os valores porcentuais atingidos pelas cultivares foram baixos, destacan do-se, apenas, a cultivar Roxa Chata como a mais sensivel, produzindo 3,138 de plantas florescidas e diferindo significa tivamente do controle. As comparações das médias efetuadas para o carāter produção mostraram que as cultivares Pira Dura e Barreiro SMP-III diferiram do controle. A cultivar Barreiro SMP-III produziu em média $2,0 \mathrm{~kg}$ a mais que a do controle, enquanto que a cultivar Pira Dura não chegou a produzir metade da produção alcançada pela Barreiro. As demais cultivares não diferiram significativamente do controle.

Convém ressaltar, que os resultados obtidos mostram que o S.C.I possibilita à todas as cultivares expressarem suas plenas potencialidades, pois é realizado em um período favorável para a cultura da cebola.

6.2. Sistema de cultivo de buibinho de verão (S.C.II)

As análises de variância mostraram que houve. diferenças significativas, pelo teste $F$, para todos os caracteres analisados (Tabela 3). Os coeficientes de variação das anālises situaram-se entre 6,018 e 25,648 , sendo que 0 menor valor fol para o caráter número de bulbos comerciais e o maior para o caráter florescimento prematuro.

As médias dos quatro caracteres, bem como as comparaçōes com o controle feitas pelo teste "t", são apre- 
sentadas na Tabela 4. Para o caráter florescimento prematuro os valores médios encontrados foram baixos, sendo que somente a cultivar Roxa Chata diferiu das demais, apresentando 2,08 de plantas florescidas prematuramente de um total de 40 plantas.

Quanto ao caráter plantas improdutivas, as cultivares Baia Precoce de Piracicaba, Composto Baia Bulbinho, $\mathrm{F}_{1}$ (Baia x Barreiro) e Pira Ouro, comportaram-se de maneira semelhante, não diferindo significativamente do controle. A cultivar Barreiro SMP-III apresentou indices porcentuais elevados de plantas improdutivas. As cultivares Roxa Chata e Pira Tropical A/R, nas condições ensaiadas, apresentaram exce lentes comportamentos, com minimas porcentagens de plantas im produtivas, 0,638 e $5 \%$, respectivamente, de um total de 40 plantas.

o caráter número de bulbos comerciais expresso em porcèntagem indicou pelo teste de médias, que a cultivar Barreiro SMP-III diferiu do controle, com um valor médio de $21,88 \%$ de bulbos comerciais. As demais cultivares não diferi ram estatisticamente do controle, apresentando valores que va riaram de 68,138 a 93,758 .

Na avaliação do caráter produção de bulbos comerciais, as cultivares Roxa Chata e Pira Tropical A/R apresentaram valores superiores em média $1,5 \mathrm{~kg} /$ parcela de $2 \mathrm{~m}^{2}$ ao 
do controle, significativo ao nível de $5 \%$ de probabilidade.

A produção da cultivar Barreiro SMP-III foi in significante nas condições do experimento, produzindo em média apenas $2,31 \mathrm{~kg} /$ parcela de $2 \mathrm{~m}^{2}$. As demais cultivares nao diferiram estatisticamente do controle.

6.3. Sistema de cultivo de bulbinho de inverno (S.C.III)

Na Tabela 5 são apresentados os quadrados médios das análises de variância individuais para os caracteres estudados, observando-se que, pelo teste F, foram detectadas diferenças significativas ao nível de $5 \%$ de probabilidade, pa ra todos os caracteres. Os coeficientes de variação foram re lativamente baixos, exceto para o caráter plantas improdutivas $(30,298)$, indicando que o ensaio foi conduzido com boa precisão experimental. Ressalte-se o fato de que o caráter plantas improdutivas tem apresentado valores bastante elevados do coeficiente dé variação em todos os ensaios.

Os resultados obtidos pela aplicação do teste " $t$ " constam da Tabela 6 . Todas as cultivares apresentaram plantas florescidas prematuramente nas condições do ensaio. Entretanto, as cultivares Pira Tropical, seleções $A / C$ e $A / R$, foram as mais prejudicadas apresentando valores acima de 198. A cultivar Pira Dura foi a menos afetada com valor um pouco acima de 18 de plantas florescidas. As novas cultivares Pira 
Lopes e Pira Ouro destacam-se, também, pela menor influência que sofreram para manifestação deste carāter.

O maior valor para o caráter plantas improduti vas foi observado na cultivar Baia do Cedo SMP-IV (controle) com 5,948. As demais cultivares não diferiram estatisticamen te do controle, apresentando valores inferiores à 2,0\% de plan tas improdutivas.

As cultivares Pira Lopes, Pira Ouro e Pira Dura apresentaram-se superiores as demais cultivares e ao controle, na avaliação do carāter número de bulbos comerciais, com valores acima de $90 \%$ num total de 40 plantas.

A cultivar Baia do Cedo SMP-IV (controle), na avaliação do carāter produção de bulbos comerciais, apresentou valor superior $\left(7,09 \mathrm{~kg} / 2 \mathrm{~m}^{2}\right)$ as demais cultivares, diferindo significativamente daquelas. A cultivar que apresentou menor valor de produção foi a Pira Dura com $3,84 \mathrm{~kg} / 2 \mathrm{~m}^{2}$.

\subsection{Anälise conjunta dos sistemas de cultivo}

As análisesconjuntas dos três sistemas de cultivo, avaliando os caracteres florescimento prematuro, plantas improdutivas, número de bulbos comerciais e produção de bulbos comerciais, encontram-se na Tabela 7. Observa-se que - fator cultivares foi significativo apenas para o carāter florescimento prematuro, indicando que as condiçōes ambien- 
tais influenciam as cultivares na expressão deste caráter. Res salte-se que quando utilizou-se o quadrado médio do resíduo, no teste $F$, houve diferenças significativas a $5 \%$ para a interação cultivares comuns $x$ sistemas de cultivo, indicando que as cultivares comuns apresentaram comportamentos distintos em cada sistema de cultivo. Para contornar esta situação, um tanto complexa, utilizou-se o procedimento indicado por PIMEN TEL GOMES (1978), em que o teste F para as cultivares comuns foi feito contra o quadrado médio da interação, sendo que, des se modo, não foi possivel detectar diferenças significativas entre as cultivares, para os caracteres de plantas improdutivas, número de bulbos comerciais e produção de bulbos. Os demais caracteres, como demonstram os resultados das análises, não pareceram sofrer grande influência das condições ambientais a que foram submetidas as cultivares. Os coeficientes de variação situàram-se entre os valores 3,898 e 27,738 , destacando-se o fato do maior valor ser para o caráter plantas improdutivas.

Na Tabela 8 são apresentadas as médias das qua tro caracteres nos três sistemas de cultivo considerados. As médias do carāter florescimento prematuro foram comparadas através do teste de Tukey. Observa-se que as cultivares podem ser agrupadas de acordo com o seu comportamento médio, nos três sistemas de cultivo, da seguinte maneira: Grupo A - representado pelas cultivares que apresentaram menor tendência ao florescimento prematuro, não diferindo estatisticamente en 
.34 .

tre si, mas que diferiram das demais cultivares, que são: Com posto Baia Bulbinho, Baia Precoce de Piracicaba e $F_{1}$ (Baia $x$ Barreiro); Grupo B - incluíndo as cultivares Pira Ouro; Roxa Chata e Pira Dura, sendo que esta ültima não diferiu estatisticamente do grupo C; Grupo C - representado pelas cultivares Baia do Cedo SMP-IV e Pira Lopes; Grupo D - inclui as cultiva res Barreiro SMP-III e Pira Tropical seleção A/R; e Grupo E representado pela cultivar Pira Tropical seleçāo A/C, que apresentou o maior valor para o caráter florescimento prematu ro. 
7. DISCUSSR̃O

Para a indústria de sementes de hortaliças, 0 ideal seria a existência de cultivares de cebola que ..fossem versäteis nos diferentes sistemas de cultivo, bem como adapta tadas as diferentes latitudes e microclimas. Assim, haveria possibilidades de obtenção de sementes em larga escala, utili zando-se de poucas cultivares e reduzindo-se os custos operacionais. Experiências quanto ao comportamento varietal da ce bola face às condições ambientais, evidenciam que não existe a cultivar ideal.

Entre os inúmeros fatores ambientais que exercem influência na adaptação de cultivares de cebola, em uma mesma latitude, sem dúvida nenhuma, o fator temperaturas extremamente baixas ou elevadas é o mais importante. Seu efeito no cultivo de inverno é muito mais evidenciado na expressão do caráter florescimento prematuro, que se caracteriza pe la emissão da haste floral, antecedendo a bulbificação da 
planta de cebola. Sob o ponto de vista de melhoramento o desejāvel seria que as cultivares florescessem com exigências minimas de baixas temperaturas, enquanto que em plantios comerciais de cebola este caráter torna-se limitante ao cultivo de determinadas cultivares.

O sistema de cultivo de cebola de inverno apre senta um periodo de plantio situado entre os meses de março a junho, que está estreitamente relacionado ao aparecimento do caráter florescimento prematuro. Os plantios efetuados em março-abril são os que favorecem a sua maior expressão (COSTA, 1964). A medida que os plantios são feitos em maio-junho a tendência ao florescimento prematuro decresce, devido ao fa to dos plantios tardios coincidirem com as temperaturas mais elevadas dos meses de setembro a outubro, que não induzem 0 florescimento prematuro.

No presente trabalho, a avaliação de novos cưl tivares no sistema de cultivo de inverno, foi realizado com plantios em junho, que é o período mais favorável ao cultivo da cebola. Observa-se que as novas cultivares não apresentaram florescimento prematuro, comportando-se de maneira similar à cultivar Baia do Cedo SMP-IV (controle). Entretanto, na cultivar Roxa Chata, que é um material com menos exigência de temperatura para florescimento, houve manifestação do carāter, apresentando cerca de $2 \%$ de plantas florescidas. Esta cultivar é um material origlnado de seleção intrapopulacional na 
variëdade Conjumatlan, feita em Piracicaba (COSTA, 1978). Sua tendência ao florescimento não foi alterada pela seleção, devido ao fato de ter sido efetuada no sistema de cultivo de vẹ rão, quando as condições ambientais não induzem o florescimen to prematuro. Deduz-se então, ser esta a única causa da cultivar Roxa Chata diferir do controle.

Observa-se no sistema de cultivo de bulbinho de verão que a incidência de plantas florescidas foi mínima. Entretanto, a segunda etapa deste sistema de cultivo, que con siste do plantio de bulbinho, ocorre em condições de fotoperiodismo e temperaturas decrescentes, propícias à manifestação do carāter florescimento prematuro. Uma possível explica Ção para a baixa incidência do fenômeno deve estar relacionada com as condições ambientais em que os bulbinhos estão submetidos no período de armazenagem, onde as temperaturas eleva das seriam ideais para induzirem a desvernalização dos mesmos. Nota-se que apenas a cultivar Roxa Chata apresenta plan tas florescidas prematuramente, devido a sua sensibilidade à temperaturas relativamente amenas. Segundo VALE (1972), no Estado de são Paulo, quando as condições climáticas de inver- no ocorrem antecipadamente e são relativamente rigorosas, as plantas de cebola originadas de bulbinhos são induzidas a flo rescerem prematuramente.

Quando o cultivo'é efetuado pelo sistema de cultivo de bulbinho de inverno, ocorre uma tendência geral das 
cultivares florescerem precocemente. Este fato é análogo ao que ocorre com os plantios de bulbinho em países de clima tem perado, onde o inf́cio da primavera é caracterizado por temperaturas amenas (THOMPSON e SMITH, 1938). Constatou-se que a cultivar Pira Tropical A/R expressou com maior intensidade o caráter florescimento prematuro. Esta cultivar é originária de cruzamento de Conjumatlan com Baia do Cedo, ambas são sensíveis à indução ao florescimento prematuro em temperaturas prrevalescentes no inverno de Piracicaba.

Os coeficientes de variação relativos ao carāter florescimento prematuro, observados nos três sistemas de cultivo, indicaram que os ensaios foram efetuados com boa pre cisão experimental, sendo que no sistema de cultivo de inverno o valor foi inferior ao encontrado por ZIMMERMANN (1973).

o comportamento das novas cultivares em relação aos três sistemas de cultivo, caracterizado pela análise de variância conjunta, revela aspectos consistentes quanto a - sensibilidade ao florescimento prematuro. Tanto assim, que existe a possibilidade de tentar-se agrupar as cultivares de cebolà através da expressividade do caráter em questão, do se guinte modo: cultivares consideradas como menos sensiveis, cô mo as Baias, selecionadas para cultivo de bulbinho, e o híbri do Baia x Barreiro; as do grupo intermediārio representados por Pira Ouro, Pira Dura e Roxa Chata; e as restantes incluidas no grupo das cultivares com maior reação de sensibilidade ao florescimento prematuro. Deve-se frizar, no entanto, que 
os resultados obtidos na análise conjunta e no teste de médias, onde utilizou-se a metodologia apresentada por PIMENTEL GOMES (1978), devem ser aceitos com cautela, principalmente, porque algumas cultivares não estavam presente em todos os sistemas de cultivo analisados e as mêdias sofreram um ajuste especial para efeito de comparação entre elas. A precisão ex perimental da análise conjunta pode ser considerada satisfató ria, tendo em vista que os coeficientes de variação das anāli ses individuais foram baixos.

Os valores obtidos de plantas florescidas prematuramente nos sistemas de cultivo de inverno e cultivo de bulbinho de verão, podem ser considerados baixos, inclusivepa ra as cultivares mais sensíveis, não constituíndo um fator li mitante ao cultivo de qualquer uma das cultivares avaliadas, nos respectivos períodos de plantio. Entretanto, estas obser vações não podem ser extensivas ao sistema de cultivo de bulbinho de inverno, onde a incidencia de plantas que floresceram precocemente foi considerado elevado. Assim, hā restrição do uso de algumas cultivares nesse sistema. Sugere-se que, o plantio dos bulbinhos possam ser adiados até agosto para que as plantas originadas destes, escapem das condições crít cas de inverno com um bom desenvolvimento vegetativo, sem ocorrer a indução ao florescimento.

Até agora, a abordagem da ocorrência de flores cimento prematuro esteve restrito ao seu aspecto indesejável, 
em plantios com fins comerciais. Todavia, outro aspecto importante desse caräter refere-se à viabilidade da produção de sementes nas condições tropicais. Tanto para a indústria de sementes como para o melhoramento da cebola, é necessário que as cultivares floresçam com mínimas exigências de baixas temperaturas. O sistema de cultivo de bulbinho de inverno seria, evidentemente, a alternativa mais vantajosa para o florescimento das cultivares de cebola. Desse modo, obtém-se as sementes utilizando um esquema anual, onde pelo método convencional exigiria dois anos. Sugere-se que ensaios especiais sejam efetuados, com o intuito de caracterizar a viabilidade do esquema anual de obtenção de semente: de cebola das novas cultivares de verão.

O nümero de plantas improdutivas é também um outro carāter indesejāvel, que reduz a produtividade varietal, As plantas improdutivas são aquelas que por ocasião da colheita não formaram bulbos comerciais, fato esse determinado por causas intrínsecas e extrínsecas à planta, ou seja, causas de natureza genética e não genētica (SCULLY et alii, 1945; AUNG e PETERSSON, 1974; JONES e MANN, 1963). A incidên cia de plantas improdutivas no sistema de cultivo de inverno foi inferior a 5\%, como pode ser observado na Tabela 2. Esta baixa incidência pode ser explicada pelo fato de que o período de cultivo coincide com valores de fotoperíodo e temperatü ras ascendentes por ocasião da bulbificação. Além do mais, os processos de nitrificação no solo neste período são acele- 
rados, evitando que o acúmulo de elevados níveis de nitrogênio interfira na bulbificação das plantas.

No sistema de bulbinho de verão o carāter plan tas improdutivas manifesta-se de maneira acentuada, destacando-se o fato de que, algumas cultivares, como a Barreiro SMPII e o híbrido (Baia x Barreiro), apresentarem maior grau de manifestação desse carāter. A cultivar Barreiro é conhecida por pertencer ao grupo de cultivares de dias curtos e de matú ração tardia, caracterização feita no cultivo de inverno. As condiçōes de fotoperiodismo e temperaturas decrescentes, prevalecentes no período do sistema de cultivo de bulbinho de ve rão, requer cultivares do grupo de dias curtos e com maturação precoce que possibilitem a bulbificação das plantas. Segundo THOMPSON e SMITH (1938), quando cultivares tardias são utilizadas em fotoperíodos insuficientes, as plantas formam folhas novas indefinidamente sem bulbificarem. Esta observação vem corroborar a necessidade de cultivares específicas pa ra os sistemas de cultivo, quando se considera o caráter plan tas improdutivas.

Um fato curioso é observado quanto ao comporta mento da cultivar Barreiro SMP-III no sistema de cultivo de bulbinho de inverno. Esta cultivar, juntamente com as cultivares Pira Lopes, Pira Ouro, Pira Dura e Pira Tropical A/R apresentaram valores mínimos de plantas improdutivas. Evidencia-se que o emprego do conceito de maturidade, vem sendo em- 
pregado de maneira relativa. Portanto, propõe-se que a classificação das cultivares concernente à maturidade seja feita em função do sistema de cultivo a ser empregado; pois como já foi observado as cultivares comportam-se de maneira diferencial em função do sistema de cultivo. Todos esses fatos, indicam que o sistema de cultivo de bulbinho de verão é o método mais indicado para efetuar seleção contra o caráter indese jável plantas improdutivas, pois fornece condições para methor exibição de contraste entre as cultivares.

Os coeficientes dè variação para as análises do caráter plantas improdutivas nos três sistemas de cultivo, mantiveram-se relativamente altos. Porém, estes coeficientes apesar de altos, parecem serem normais na avaliação deste carāter, conforme demonstram os resultados obtidos por ZIMMERMANN (1973), YOKOYAMA (1976) e BUSO (1978).

Pela análise de variância conjunta dos três sistemâs de cultivo, não foi detectada diferença significativa entre o comportamento médio das cultivares em relação ao caráter plantas improdutivas. Talvez, demonstrando haver ce $\underline{r}$ ta uniformidade das cultivares na manifestação desse caráter nos três sistemas de cultivos; ou então, que a metodologia utilizada para avaliação desse carāter nas cultivares, relacionada aos sistemas de cultivos, tenha sido ineficiente na detecção de possiveis diferenças havidas entre as cultivares. 
A produtividade de cebola é avaliada pelo núme ro de bulbos comerciais ou pelo peso dos bulbos. Todavia, a ocorrência de plantas florescidas precocemente e de plantas que não bulbificaram, tendem a reduzir o número de bulbos co merciais, alterando diretamente a produtividade das cultivares. A cultivar de cebola ideal seria aquela que num determi nado sistema de cultivo não apresentasse os caracteres indese jáveis de florescimento prematuro, e plantas improdutivas. Des se modo, obteria-se o máximo de plantas bulbificadas e, conse quentemente, maior produção por unidade de área.

Observa-se que no sistema de cultivo de cebola de inverno as cultivares não diferem da Baia do Cedo SMP - IV. (controle) e apresentam valores superiores a 888 de bulbos co merciais. Este fato, novamente, evidencia que o sistema de cultivo de inverno coincide com o período mais favorável ao cultivo da cebola na região do Estado de são Paulo, produzindo-se o máximo de plantas bulbiricadas. Embora as cultivares não se diferenciem do controle para o caráter número de bulbos comerciais, quando avaliaram-se as produções observou-se que as cultivares Barreiro SMP -III e Pira Dura diferiram signi ficativamente, indicando que as cultivares apresentam diferen ças quanto ao peso unitário dos bulbos. Para a cultivar Barreiro SMP-III, esta diferença poderia ser explicada considerando o seu caráter de maturidade tardia, pois é sabido que cultivares de maturação tardia possibilitam o desenvolvimento 
mais vigoroso da planta, dando condições para a formação de bulbos com maior tamanho e, consequentemente, com maior peso. BUSO (1978) e DOWKER et alii (1976) relatam que as produções também podem ser mantidas devido a uma compensação individual das plantas remanescentes.

A cultivar Pira Dura, que também diferiu do controle, porém com um comportamento inverso, destaca-se por seu baixo valor de produção; uma possível explicação deste comportamento deve-se ao fato de que esta cultivar apresenta teores elevados de sólidos solúveìs, pois de acordo com COSTA (1978) e BUSO (1978), cultivares com esta característica, independente de serem de maturidade precoce ou tardia, demonstram menor produtividade. Uma alternativa para o aumento da produtividade da cultivar Pira Dura seria através do aumento da população de plantas por área. Portanto, sugere-se que no vos ensaios sejem feitos utilizando-se para esta cultivar uma maior lotação de plantas por parcela, a fim de testar a exequibilidade de um plantio mais denso, sem que haja prejuizo do tamanho dos bulbos.

No sistema de cultivo de bulbinho de verão, eliminando-se os efeitos de natureza ambiental em função do tạ manho do bulbinho, a maturidade das cultivares que é de natureza genética, è o fator mais importante que limita o bom com portamento das cultivares de dias curtos. Cultivares conside radas tardias, com a Barreiro, apresentam um comportamento 
consideravelmente inferior, produzindo valores irrisórios de bulbos comerciais e, consequentemente, baixa produção por área. Para contornar os problemas surgidos com a cultivar Barreiro SMP-III, VALE (1972), sugere a antecipação do plantio dos bulbinhos, caso estes não apresentem dormência, para janeiro prolongando-se até a segunda quinzena de fevereiro.As cultivares Roxa Chata e Pira Tropical A/R destacaram-se como as mais promissoras neste sistema de cultivo, superando a Baia do Cedo SMP-IV (controle) em nümero de bulbos comerciais e produção.

Quanto ao comportamento das cultivares no sistema de cultivo de bulbinho de inverno, observa-se que as novas cultivares Pira Lopes, Pira Ouro e Pira Dura mostraram ca pacidade de bulbificação equivalente à Baia do Cedo SMP-IV . Estas cultivares podem ser consideradas como precoces para o sistema de cultivo em questão, produzindo valores acima de 90 \& de bulbos comerciais. Entretanto, a produção de bulbos comerciais destas cultivares não alcançou $6,5 \mathrm{~kg} / 2 \mathrm{~m}^{2}$, enquan to que a cultivar Baia do Cedo SMP-IV superou todas as demais $\left(7,09 \mathrm{~kg} / 2 \mathrm{~m}^{2}\right)$, com diferenças estatisticamente significativas. As produções obtidas neste sistema de cultivo podem ser consideradas satisfatórias, em vista da alta incidêncía de florescimento prematuro, originados por condições estacionais desfavoráveis que influênciaram negativamente no potencial pro dutivo das referidas cultivares. A cultivar Pira Dura foi a que apresentou a menor produção de bulbos comerciais. 
Obteve-se uma precisão experimental satisfatōria na avaliação dos caracteres nümero de bulbos comerciais e produção de bulbos, sendo que os coeficientes de variação encontrados para estes caracteres foram superior e inferior, respectivamente, ao encontrado por BUSO (1978).

As anālises de variância conjunta dos sistemas de cultivos, avaliando-se os caracteres número de bulbos comerciais e produção de bulbos por ārea não detectaram diferen ças significativas entre as cultivares.

O novo sistema de cultivo de cebola descrito no presente trabalho, sistema de cultivo de bulbinho de inver no, oferece inúmeras vantagens, dentre elas destaca-se as seguinte: o escalonamento das épocas de plantios a partir de agosto até outubro, possibilitando colheitas dos bulbos ria pré-entressafras; a conservação dos bulbinhos durante o inver no seria favorecida pelo período sêco, de baixas temperaturas e pluviosidades, havendo menor inncidência de bulbinhos apodre cidos e possibilitando que o armazenamento fosse feito até mesmo no campo; o cultivo è efetuado num período extremamente favorāvel à bulbificação; e haverịa possibilidade do uso de mecanização para o plantio dos bulbinhos, assim como para o controle de ervas daninhas. A limitação principal do novo mé todo de cúltivo: que é o florescimento prematuro das plantas, pode ser contornado através de manejos especiais. De certa maneira pode também ser vantajosa a mínima exigência para o 
florescimento, se esta for utilizada em programas de melhoramento da cebola, assim como, para produção de sementes comerciais nas condiçöes tropicais. o diagrama esquemático da pro posição do novo sistema de cultivo em reląção aos demais métó dos convencionais, constam na Figura 1.

Observa-se na Figura 1 que o sistema de cultivo de bulbinho de inverno pode ser integralizado ao sistema de cultivo de verão. Surge como uma opção de continuidade de cultivo para o cebolicultor, que poderia aproveitar os bulbos com peso inferiores a $50 \mathrm{~g}$ os mesmós originados da extrema competição entre plantas que se observa quando são utilizado semeaduras direta sem precisão; estes bulbos possuem valor ge nético ṕois não constituem bulbos refugos de espaçamentos nor mais. Plantando-os no segundo semestre pelo sistema de cultí vo de bulbinho de inverno, consegue-se duas colheitas por ano.

Caso haja interesse específico de produção de bulbinho para uso no sisțema de cultivo de inverno, as semeaduras poderiam ser efetuadas nos meses de novembro a dezembro. Contudo, sugere-se que experimentos específicos sejan efetuados visando determinar o periodo mais favorável para semeaduras, densidades adequadas de semeaduras, tamanho ideal de bul binho e a melhor época para o plantio. 
8. CONCLUSOES

O presente trabalho permitiu as seguintes conclusões:

- Constatou-se a viabilidade do sistema de cul tivo de bulbinho de inverno em ser integrado ao sistema de cultivo de verão, permitindo a continuidade do cultivo da cebola pelo agricultor no decorrer do ano e, consequentemente, a obtenção de duas colheitas.

- O sistema de cultivo de bulbinho de inverno é um método eficiente para obtenção de sementes no esquema anual.

- As cultivares Pira Tropical seleções $A / R$ e A/C mostraram-se inadequadas ao plantio no sistema de cultivo de bulbinho de inverno, por apresentarem, no plantio de' ju1ho, maior sensibilidade ao florescimento prematuro. 
.49 .

- Dos caracteres avaliados, o florescimento

prematuro é o mais influenciado pelas condiçōes ambientais a que foram submetidas as cultivares.

- As novas cultivares Pira Lopes, Pira Dura e Pira Ouro podem ser classificadas como de maturação precoce em relação ao sistema de cultivo de bulbinho de inverno e equivalentes a Baia do Cedo SMP-IV.

- As cultivares Barreiro SMP-III, Roxa Chata e Baia do Cedo SMP-IV foram as que obtiveram as melhores produf̧ões nos sistemas de cultivo de inverno, cultivo de bulbinho de verão e cultivo de bulbinho de inverno, respectivamente. 
9. SUMMARY

This research, aims the caracterization of new onion cultivar performance under three crops systems, as well $\because$ the comparison of the winter onion-set technique in relation to other conventional onion crops.

The used materials envolve ten onion cultivars and one inter-varietal hybrid. The trials of the three onion crops were with random block design. The considered characteres were: bolting, unprodutive plants, commercial bulbs number and yield.

In the conventional winter crops and summer onion-set "Roxa Chata" cultivar, had highest value of bolting. In the winter onion-set crop, the "Pira Tropical" cultivar selection $A / R$ and $A / C$, was superior over others and also to the control. "Pira Dura", was the cultivar with lowest bolting tendency. Concerning the unproductive plant 
occurrence in the summer onion-set crop, Barreiro SMP-III cultivar, performs by its high number of unproductive plants in contrast with low number of "Roxa Chata", "Baia do Cedo SMP-IV" and "Pira Ouro", have higher and lower value of unproductive plants, respectively, in the winter onion-set crop. In the evaluation of number of commercial bulbs, it was not detected statistical differences among cultivar and control, for winter crops conditions. However, in the summer onion-set crops, "Barreiro SMP-III", had poor performance concerning commercial bulb yield. In the winter onion-set crop, "Pira Lopes", "Pira Ouro" and "Pira Dura" were outstanding cultivars concerning to commercial bulbs yield.

In relation to the yield, the most productive cultivars in the winter, summer onion-set and winter onion-set crops were respectively "Barreiro SMP-III", "Roxa Chata" and "Baia do Cedo SMP-IV".

The winter onion-set crop, by its results, indicate the possibility of application of onion seed. production in annual scheme instead of biannual one. Another advantage is its coupling with summer crops, allowing two harvests for the onion grower.

Bolting is the character which exert most influence in the onion cultivar performance in all onion crop systems. It suggested changes for late planting in august of onionsets, to avoid bolting of most sensitive cultivar. 
10. LITERATURA CITADA

ABDALLA, A.A. e L.K. MANN, 1963. Bulb development in the onion and the effect of storage temperature on bulb rest. Hizgardia. Berkeley, 35:85-112.

AUNG, L.e C.E. PETERSON, 1974. Gibberellin - like substances of dormant and non-dormant bulbs of Allium cepa L. Journal of the American Society for Horticultural Science. Virginia, 99:(3):279-281.

BARTLETT, M.S., 1947. The use of transformation. Biometrics. Washington, $3: 39-52$.

BUSO, J.A., 1978. Estimativas de parâmetros genéticos de caracteres de planta e bulbo de cebola (Allium cepa L. ). ESALQ/USP, Piracicaba, SP. 132 p. (Dissertação de Mestra-do) . 
CAMARGO, J.R.S. e A.A. VIANNA, 1964. Estudo de épocas de plantio de bulbinhos para produção de cebola. Revista de olericultura. Pelotas, RS., IV: 223-226.

CAMPOS, H.R., 1966. Instruções para a cultura de cebola. Inst. Agron. de Campinas, Boletim no 164, Campinas, SP. , 29 p.

COLBY, W.G.; C.J. GILGUT e H.M. YEGIAN, 1945. The culture of onion-set in the Connecticut valley. Bulletin of Massachusetts Agricultural Experiment Station. 424, 16 p. ilustrado.

COSTA, C.P., 1964. Comportamento de variedades de cebola em diferentes épocas de semeadura. In. III Reunião da S.O.B. Campinas, SP, 3 p. (mimeografado):

COSTA, C.P., 1967. Estudo da esterilidade masculina e identificação de linhas complementares (Nms, ms) da variedade brasileira de cebola Baia Periforme de Piracicaba ( Allium cepa L.) ESALQ/USP, Piracicaba, SP., 32 p. (Dissertação de Mestrado) .

COSTA, C.P., 1978. Melhoramento de cebola (Allium cepa L.) de dias curtos para sistema de cultivo. ESALQ/USP, Piracicaba, SP., 138 p. (Tese de Livre-Docente). 
COSTA, C.P. e M. DIAS, 1967. Comportamento de alguns hỉbridos experimentais de variedades de cebola. Rezatório Cien tífico do Instituto de Genética. ESALQ/USP, Piracicaba, SP., $91-94$.

DIAS, M., 1962. Instruções para a cultura de cebola pelo pro cesso de bulbinho. Parte I - Produção de bulbinho. Insti tuto de Genética, ESALQ/USP, Piracicaba, SP, 3 p. (Mimeografado).

DIAS, M., 1963. Instruções para a cultura de cebola pelo pro cesso de bulbinho. Parte I - Produção de bulbinho, 2a. ed. Melhorada. Instituto de Genética, ESALQ/USP, Piracicaba, SP, 8 p. (mimeografado).

DIAS, M., 1966. Instruções para a cultura de cebola pelo pro cesso de bulbinho. Parte II - Plantação do bulbinho. Ins tituto de Genética. ESALQ/USP, Piracicaba, SP., 8 p. (Mimeografado).

DIAS, M.; H. IKUTA e R. VENCOVSKY, 1961. Ensaios de bulbinhos de cebola, variedades, épocas e tamanhos de bulbinho. In. III Reunião da S.O.B. 3 p. (mimeografado).

DIAS, M. e C.P. COSTA, 1967. Eficiência de um ciclo de seleção massal contra florescimento prematuro na var. de cebola Barreiros. Relatório Cientifico do Instituto de Genétí ca. ESALQ/USP, Piracicaba, SP., 8I-83. 
DIAS, M. e C.P. COSTA, 1968. Se leção para a cultura do Cedo na variedade brasileira de cebola Baia Periforme Precoce. Relatório Cientifico do Instituto de Genética. ESALQ/USP, Piracicaba, SP., 125-130.

DIAS, M.; R. VENCOVSKY e C.P. COSTA, 1969. Herança para o florescimento prematuro de alguns cruzamentos de variedades de cebola. Relatório Cientifico do Instituto de Genética. ESALQ/USP, Piracicaba, SP, 143-147.

DIAS, M. e C.P. COSTA, 1970. Programa de melhoramento de cebola (Allium cepa L.) em andamento no setor de melhoramento de hortaliças do Instituto de Genética-ESALQ/USP, Pira-. cicaba, SP, 6 p. (mimeografado).

DOWKER, B.D.; R.C. HARDWICK; J.F.M. FENNEL A D.J. ANDREWS, 1976 . Genotypic and environmental correlations between leaf growth and bulb size. Annual of Applied Biology. Cambridge, $\underline{82}: 341-348$.

DRINKWATER, W.O. e B.E. JANES, 1955. Effects of irrigation and soil moisture on maturity, yield and storage of two onion hybrids. Proceedings of the American for Horticultu ral Sciences. New York, 66:267-268.

FRAPPEL, B.D., 1973. Plant spacing of onions. Journal of Horticultural Science. London, 48:19-28. 
HEATH, O.V.S., 1943. Studies in the physiology of the onion plant. I. An Investigation of the factors concerned in the flowering ('bolting') of onion grown from sets and its preservation. Part I. Production and storage of onion sets and field results. Annual of applied Biology. Cambridge, 30: $20 \mathrm{p}$.

HOLDSWORTH, M. E D.V. S. HEATH, 1950. Studies in the physiology of the onion plant IV. The influence of day-lenght and temperature on the flowering of the onion plant. Journal Experimental Botany. Oxford, 1:353-375.

HOPEN, H.J ; R.R: DEDOIPH; W.F.WHITESIDE e W. CHORNEY, 197 I. Rest period reduction in non-stored onion (Allium cepa L:) sets. Journal of American Society for Horticultural Scien ce. Virginia, $96(4): 498-501$.

JONES, H.A. E L.K. MANN, 1963. Onion and their Allies. New York, Leonnard Hill Books, $286 \mathrm{p}$.

KARMARKAR, D.V. e B.M. JOSHI, 1941. Investigations on the storage of onions. Indian Journal of Agricultural Science. New Delhi, 55 (2):72-78.

MELO, P.C.T.;1978. Seleção massal estratificada em duas popụ lações de cebola (Allium cepa L.) Baia Periforme, no vale do submédio São Francisco. ESALQ/USP. Piracicaba, SP, 72 p. (Dissertação de Mestrado). 
PIMENTEL GOMES, F., 1978. Curso de Estatística Experimental. São Paulo. Livraria Nobel. 8a. ed. 430 p.

ROBERTS, R.H. A B.E. STRUCKMEYER, 1951. Observations on the flowering of onions. Proceedings of the Annual Society for Horticultural Science. Virginia, 58:213-216.

SCULLY, N.J.; M.W. PARKER e H.A. BORTHWICK, 1945. Interation of nitrogen nutrition and photoperiod expressed in bulbing and flower stalk development of onion. Botanical Garette. Chicago, 107:52-61.

SILVA, N. 1976. Resistência em cebola (Allium cepa L.) à Col letotrichum gloeosporioides Penz (sensu ARX, 1957). ESALQ /USP. Piracicaba, SP, 67 p. (Dissertação de mestrado).

SINNADURAI, S.; I. MUKBERJEE e J. ABDU, 1971. Regulation of flowering in onions by maleic hydrazide and chlormequat. HortScience. Virginia, : 6 (5):486-487.

SNEDECOR, G. W., 1946. Statistical methods applied to experiments in agriculture and biology. Iowa state college Press. 4a. ed. 557 p.

STEEL, R.G.D. A J.H. TORRIE, 1960. principles and procedures of statistics with special reference to the biological sciences. McGraw Hill. New York. 481 p. 
THOMPSON, H.C. e O. SMITH, 1938. Seedstalk and bulb

development in the onion, Allium cepa L., Buzzetin of Cornell Agricultural Expeximent Station, Geneva, no. 708, $21 \mathrm{p}$

TRONICKOVA, E., 1977. Short day forms of onion (A. cepa L.) as applied for cultivation from fall plantation of sets. Vedeckē Práce Vỹzkumnȳch Ustavủ Rostlinné vȳroby v PrazeRuznyi. Vỹyumné üstavy rostzinné výroby, (1974)19:91-101, Praha-Ruzyne, Czechoslovakia. In: Plant Breeding Abstracts. Cambridge, $\underline{47}(2)$ no 1734 .

VAIE, E.C., 1972. Comportamento de cultivares de cebola rela cionado com épocas extremas de plantio e tamanho de bulbinho. ESALQ/USP. Piracicaba, SP, 45 p. (Dissertação de Mestrado).

WALKER, J.C.; W.C. EDMUNDSON e H.A. JONES, 1944. Onion-set production. U.S. Department of Agriculture Farmer's Bulzetim, no 1955. 21 p.

WANDERLEY, L.J.G.; M.B. WANDERLEY E A.C. LIMA, 1971. Efeito do espaçamento na produçăo e peso médio de bulbos de cebo1a. IN. XI Congresso da S.O.B. Piracicaba, l p. ( mimeografado) . 
YOKOYAMA, S., 1976. Comportamento de populações de cebola Baia Periforme (Allium cepa I.) com relação à épocas e téc nicas de cultivo. ESALQ/USP. Piracicaba, SP, 77 p. (Dissertação de Mestrado).

ZIMMERMANN, M.J.O., 1973. Efeitos da autofecundação na varie dade de cebola Barreiros (Allium cepa L.). ESALQ/USP. Piracicaba, SP, 97 p. (Dissertação de Mestrado). 
.60 .

\section{APENDICE}

11.1. Simbologia

11.2. Tabelas

11.3. Figura 
11.1. Simbologia

- FP: Florescimento prematuro (of); dados transformados para = $\log \mathrm{x}$ e valores médios apresentados em porcentagem de uma população de 40 plantas por parcela;

- PI: Plantas improdutivas (8); dados transformados para log $\mathrm{x}$ e valores médios apresentados em porcentagem de uma população de 40 plantas por parcela;

- BC: Bulbos comerciais (unidade); dados transformados para $\sqrt{y}$ e valores médios apresentados em porcentagem de uma população de 40 plantas por parcela;

- P : Produção de bulbos $\left(\mathrm{kg} / 2 \mathrm{~m}^{2}\right)$; dados não transformados e valores médios apresentados em $\mathrm{kg} / 2 \mathrm{~m}^{2}$. 
.62.

Tabela 1. Valores e significâncias dos quadrados médios das análises de variância dos caracteres estudados no delineamento de blocos ao acaso. Sistema de cultivo de inverno. Piracicaba, SP, 1975.

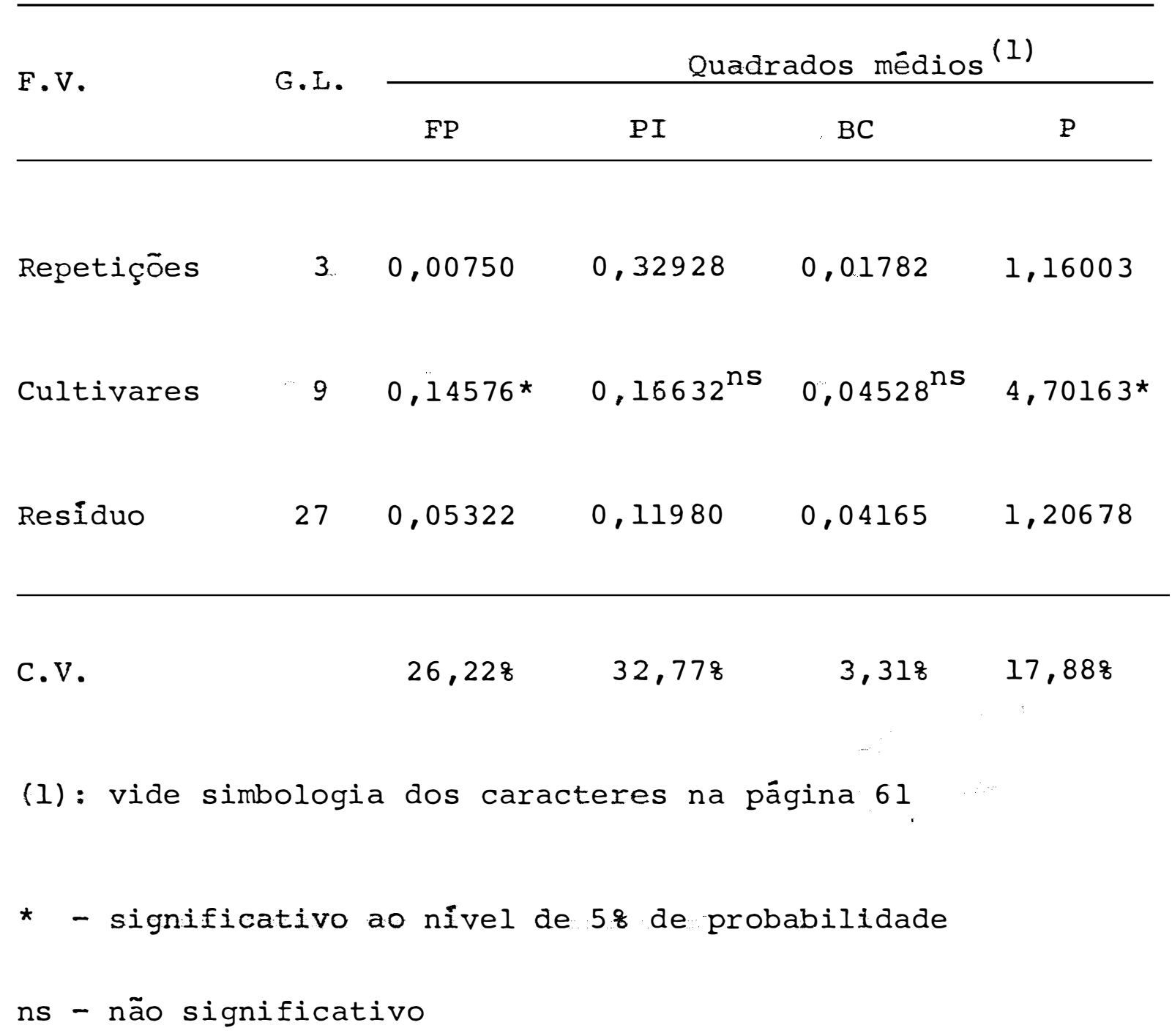


Tabela 2. Médias dos caracteres estudados para as cultivares de cebola. Sistema de cultivo de inverno. Piracicaba, SP. 1975 .

Cultivares

Caracteres (1)

$\begin{array}{llll}\text { FP } & \text { PI } & \text { BC }\end{array}$

Baia do Cedo SMP-IV

(Controle)

$0,00 \quad 0,00 \quad 100,00 \quad 6,62$

Composto Baia Bulbinho

$0,00^{\text {ns }} \quad 0,63^{\text {ns }} \quad 98,75^{\text {ns }} \quad 6,33^{\text {ns }}$

Baia Precoce Piracicaba

$0,00^{\text {ns }} \quad 1,25^{\text {ns }} \quad 93,75^{\text {ns }} \quad 5,99^{\text {ns }}$

$F_{1}$ (Baia x Barreiro)

$0,00^{\text {ns }} \quad 1,25^{\text {ns }}$

$97,50^{\text {ns }} \quad 7,01^{\text {ns }}$

Roxa Chata

$3,13^{*} \quad 1,25^{\text {ns }} \quad 95,00^{\text {ns }}=5,90^{\text {ns }}$

Barreiro SMP-III

$0,00^{\text {ns }}$

$5, \theta 0^{\text {ns }}$

$94,38^{\text {ns }}$

$8,15 *$

Pira tropical A/R

$1,88^{\mathrm{ns}}$

$1,25^{\text {ns }}$

$88,75^{\text {ns }}$

$5,21^{\text {ns }}$

Pira Ouro

$0,00^{\mathrm{ns}}$

$0,00^{\text {ns }}$

$93,13^{\text {ns }} \quad 5,71^{\text {ns }}$

Pira Dura

$0,00^{\text {ns }} \quad 2,50^{\text {ns }} \quad 93,75^{\text {ns }} \cdot 4,07 *$

Pira Lopes

$0,00^{\text {ns }}$

$1,25^{\mathrm{ns}}$

$95,63^{\text {ns }} \quad 6,46^{\text {ns }}$

(1) - vide simbologia dos caracteres na página no 61

* - significativo ao nivel de $5 \%$ de probabilidade pelo teste "t",

ns - não significativo. 
Tabela 3. Valores e significâncias dos quadrados médios das análises de variância dos caracteres estudados, no delineamento de blocos ao acaso. Sistema de Cultivo de Bulbinho de Verão. Piracicaba, SP. 1975.

\begin{tabular}{|c|c|c|c|c|c|}
\hline \multirow{2}{*}{ F.V. } & \multirow{2}{*}{ G.L. } & \multicolumn{4}{|c|}{ Quadrados médios (1) } \\
\hline & & FP & PI & $B C$ & $\mathrm{P}$ \\
\hline Repetições & 3 & 0,01246 & 0,10570 & 0,05126 & 1,28637 \\
\hline Cultivares & 7 & 0,25598 * & 1,56499 * & 4,73624 * & $21,62005^{*}$ \\
\hline Resíduo & 21 & 0,05382 & 0,19025 & 0,10918 & 0,77214 \\
\hline$c . v$. & : & 25,648 & 23,188 & 6,018 & 12,328 \\
\hline$(1):$ vide $s$ & logia & dos carac & eres na pá & gina n: 61 & \\
\hline * : signif & ivo ac & nivel de & 58 de prob & abilidade & \\
\hline
\end{tabular}


.65 .

Tabela 4. Médias dos caracteres estudados para as cultivares de cebola. Sistema de Cultivo de Bulbinho de Verão. Piracicaba, SP. 1975.

\begin{tabular}{|c|c|c|c|c|}
\hline \multirow{2}{*}{ Cultivares } & \multicolumn{4}{|c|}{ Caracteres $(1)$} \\
\hline & FP & PI & $B C$ & $\mathrm{P}$ \\
\hline $\begin{array}{l}\text { Baia do Cedo SMP-IV } \\
\text { (Controle) }\end{array}$ & 0,00 & 13,75 & 82,50 & 7,90 \\
\hline Composto Baia Bulbinho & $0,00^{\mathrm{ns}}$ & $6,88^{\mathrm{ns}}$ & $91,88^{\text {ns }}$ & $7,06^{\mathrm{ns}}$ \\
\hline Baia Precoce Piracicaba & $0,00^{\mathrm{ns}}$ & $8,13^{\mathrm{ns}}$ & $90,00^{\mathrm{ns}}$ & $5,85^{x}$ \\
\hline$F_{1}$ (Baia x Barreiro) & $0,00^{\mathrm{ns}}$ & $30,00^{\mathrm{ns}}$ & $68,13^{\mathrm{ns}}$ & $7,38^{\mathrm{ns}}$ \\
\hline Roxa Chata & $2,00 *$ & $0,63^{*}$ & $92,50^{\mathrm{ns}}$ & 9,80 * \\
\hline Barreiro SMP-III & $0,00^{\text {ns }}$ & 77,50 * & $21,89 *$ & $2,31 *$ \\
\hline Pira Ouro & $0,00^{\text {ns }}$ & $11,88^{\mathrm{ns}}$ & $86,25^{\mathrm{ns}}$ & $7,35^{\mathrm{ns}}$ \\
\hline Pira Tropical A/R & $0,25^{\mathrm{ns}}$ & $5,00 *$ & $93,75^{\mathrm{ns}}$ & $9,40 *$ \\
\hline
\end{tabular}

(1) - vide șimbologia dos caracteres na página n8 61;

* - significativo ao nivel de 58 de probabilidade pelo teste "Ł";

ns - não significativo. 
.66.

Tabela 5. Valores e significiâncias dos quadrados médios das anālises de variância dos caracteres estudados, no delineamento de blocos ao acaso. Sistema de Cultivo de Bulbinho de Inverno. Piracicaba, SP, 1979.

\begin{tabular}{|c|c|c|c|c|c|}
\hline \multirow{2}{*}{$F \cdot V$. } & \multirow{2}{*}{ G.L. } & \multicolumn{4}{|c|}{ Quadrados médios (l) } \\
\hline & & FP & $P I$ & $\mathrm{BC}$ & $\mathrm{P}$ \\
\hline Repetições & 7 & 0,03965 & 0,05415 & 0,02704 & 0,54990 \\
\hline Cultivares & 6 & 1,38305 * & $0,56281 *$ & 0,52190 * & 8,72572 * \\
\hline Residuo & 42 & 0,07239 & 0,10034 & 0,03690 & 0,53080 \\
\hline C.V. & $:$ & 14,088 & 30,298 & 3,238 & 12,258 \\
\hline
\end{tabular}

(1) : vide simbologia dos caracteres na paǵina no 61;

* : significativo ao nível de 5 \& de probabilidade;

ns : não significativo. 
.67 .

Tabela 6. Médias dos caracteres estudados para as cultivares de cebola. Sistema de Cultivo de Bulbinho de Inver no. Piracicaba, SP. 1979.

Cultivares

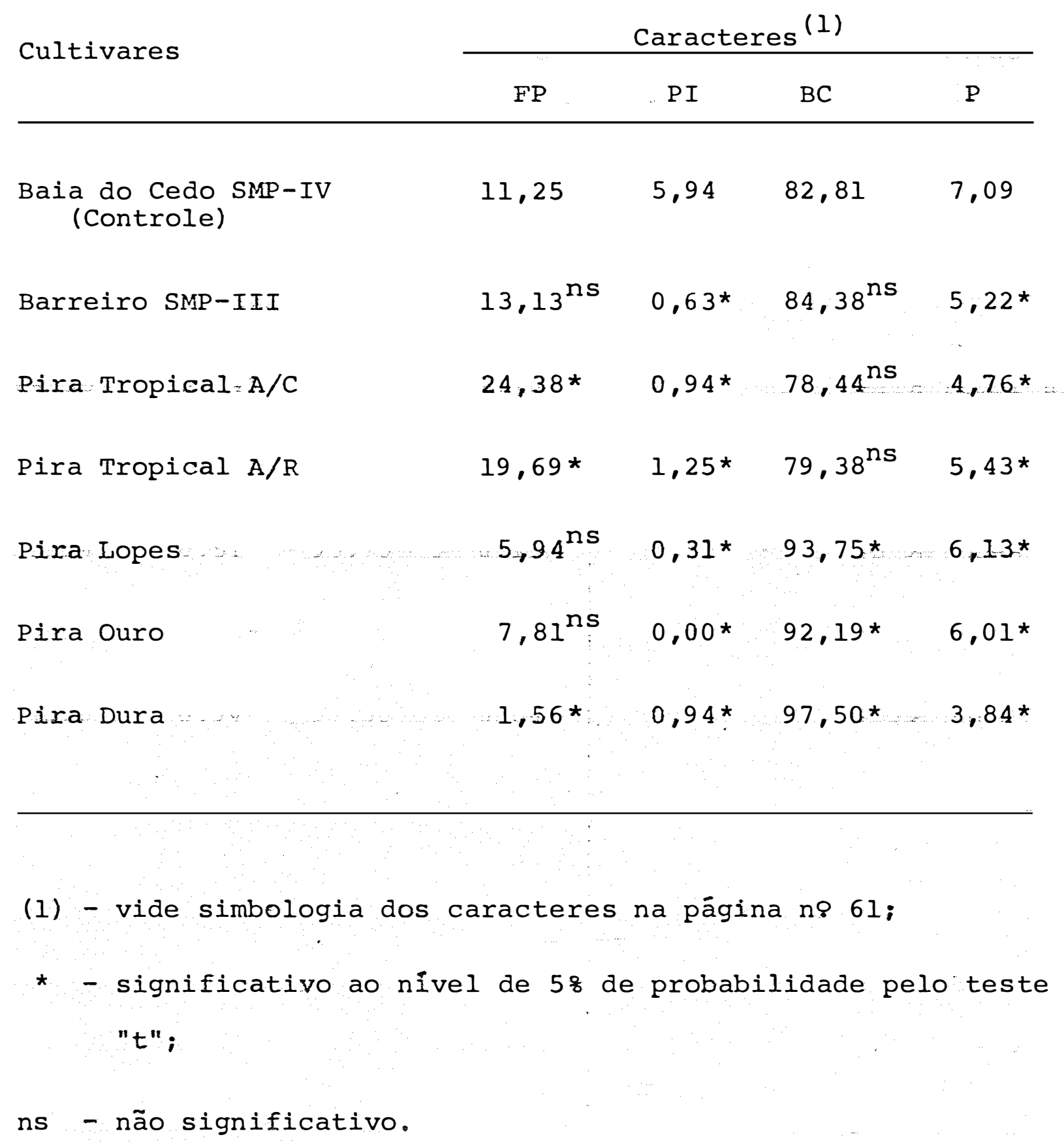

Baia do Cedo SMP-IV (Controle) 
.68.

Tabela 7. Valores e significâncias dos quadrados médios da aná lise de variância conjunta relativas aos caracteres estudados, no delineamento de blocos ao acaso com tratamentos comuns e três sistemas de cultivo. Piracicaba, SP. $1974 / 75 / 79$.

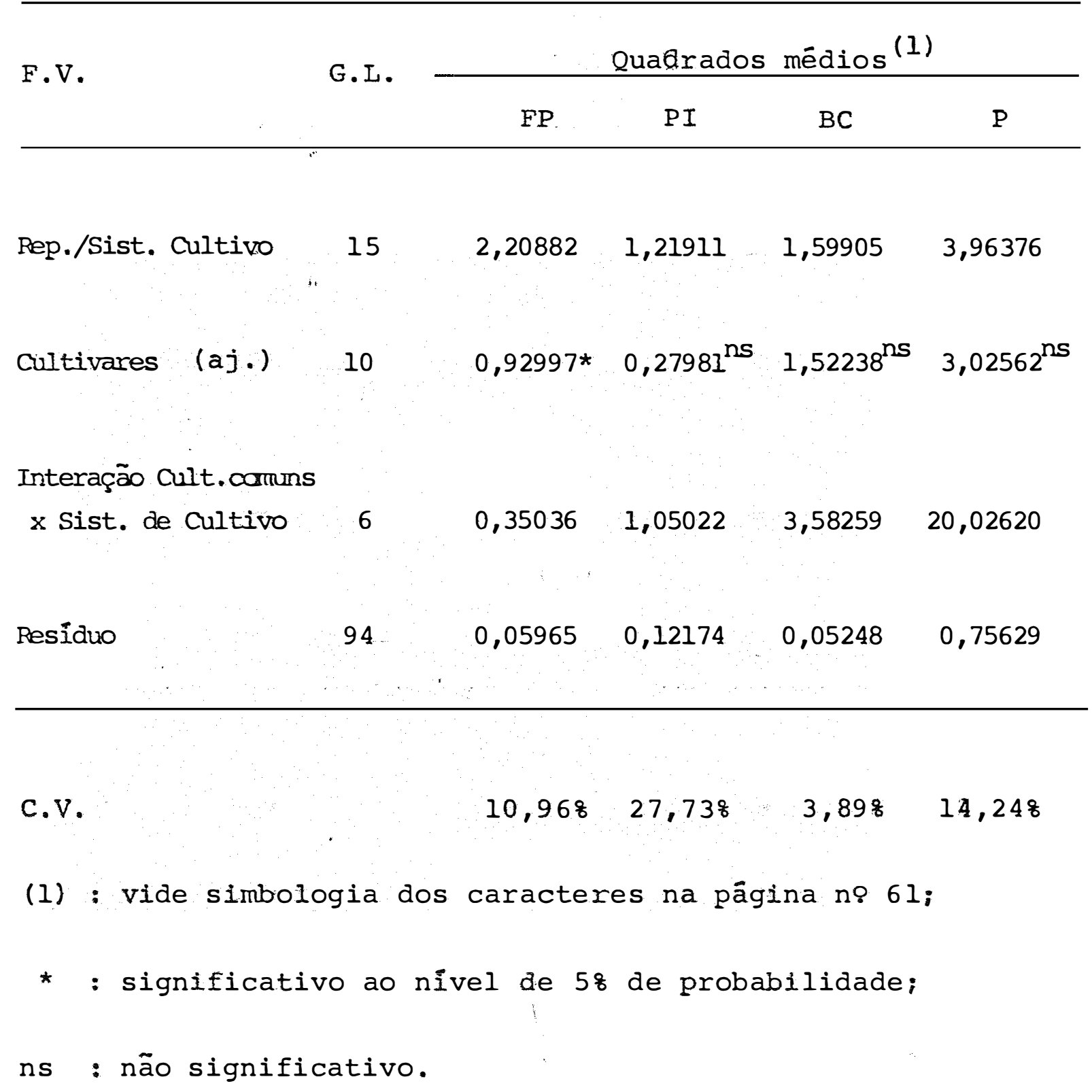


Tabela 8. Médias dos caracteres estudädos para as cultivares de cebola nos três sistemas de cultivo. Piracicaba, SP. $1974 / 75 / 79$.

CuItivares

\begin{tabular}{cccc}
\multicolumn{4}{c}{ Caracteres $^{(1)}$} \\
\hline FP $^{(2)}$ & $\mathrm{PI}$ & $\mathrm{BC}$ & $\mathrm{P}$
\end{tabular}

Baia do Cedo SMP-III (3)

$3,75^{\mathrm{C}} \quad 6,48 \quad 88,43 \quad 7,20$

Barreiro SMP-III (3)

$4,37^{\mathrm{d}} \quad 27,54 \quad 66,88 \quad 6,23$

Pira Tropical $A / R^{(3)}$

$7,27^{\mathrm{d}} \quad 3,33 \quad 87,30 \quad 6,68$

Pira Ouro (3)

$2,60^{\mathrm{b}} \quad 3,93 \quad 95,31 \quad 6,37$

Composto Baia Bulbinho

$0,00^{\mathrm{a}} \quad 3,75 \quad 90,52 \quad 6,70$

Baia Precoce Piracicaba

$0,00^{\mathrm{a}} \quad 4,69 \quad 91,88 \quad 5,92$

Roxa Chata

$2,57^{\mathrm{b}}$

0,94

93,75

7,85

$F_{1}$ (Baia x Barreiro)

$\begin{array}{lllll}0,00^{a} & 20,62 & 82,81 & 7,20\end{array}$

Pira Dura

$0,78^{\mathrm{bc}}$

1,72

95,62

3,95

Pira Lopes

$2,97^{\mathrm{C}}$

0,78

94,69

6,30

Pira Tropical A/C

$19.69^{\mathrm{e}}$

0,94

78,44

4,76

(1) - vide simbologia dos caracteres na página no 61 ;

(2) - cultivares avaliadas simultaneamente nos três sistemas de cultivo;

(3) - médla seguida de mesma letra não apresenta diferença significativa ṕelo teste de Tukey ao nivel de 58 de pro babilidade. 


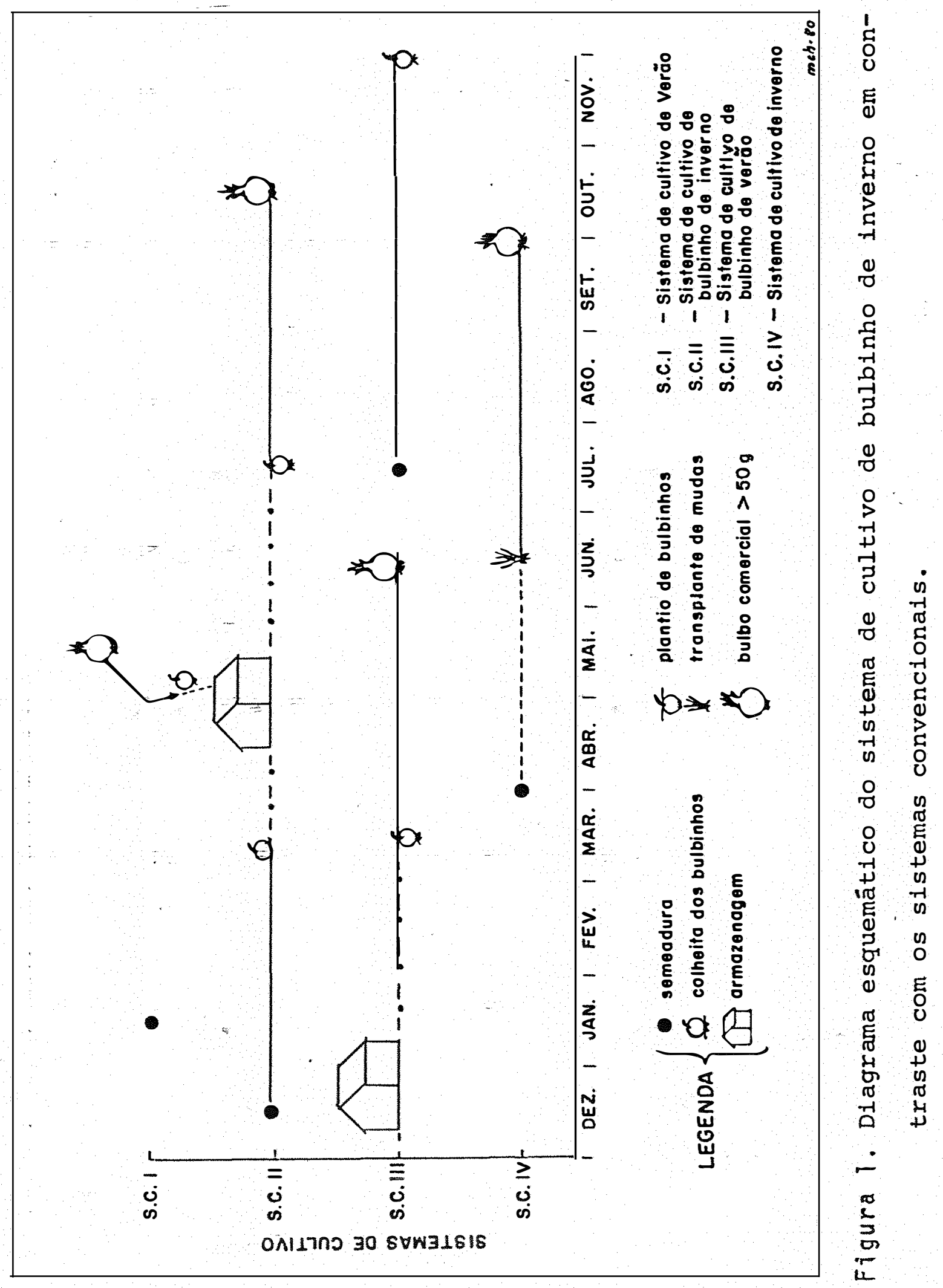

